\title{
Influential Factors in the Survival Rate of Trauma Victims until Discharge from the Hospital
}

\author{
Tahereh Najafi Ghezeljeh ${ }^{1}$, Shayan Chegini ${ }^{2}$, Shima Haghani ${ }^{3}$, Payman Namdar $^{4}$
}

\begin{abstract}
Background \& Aims: Trauma is an important public health concern in the world. With the advancement of science and technology and the industrialization of societies in the past century, trauma and its complications have become an important issue. Trauma is the most common cause of death and disability in people aged 1-44 years. Furthermore, trauma is the leading cause of reduced life expectancy and years of life lost worldwide. The most important measure to be taken in the event of a crisis is to maintain the survival of the casualty, prevent permanent complications before basic treatment, return the casualty to pre-injury living conditions as soon as possible, and provide emergency assistance quickly and intelligently. Since traumatic injuries may deteriorate without intervention and time resolution, posttraumatic survival rate largely depends on time. The chances of survival after trauma in the case of severely injured patients increase with their timely transfer to treatment centers. Pre-hospital emergency medical services (EMS) are an integral part of the healthcare delivery system and play a key role in the provision of pre-hospital services and patient transfer to medical centers. The purpose of such medical services is to provide appropriate treatment at the right place and time by using available resources. The correct operation of different parts of this system results in the rapid and timely dispatch of ambulances to the patientchr('39')s bedside and the prevention of death and disabilities. Qazvin province has a strategic location in terms of transportation and industry. Qazvin is the communication route of more than 13 provinces in Iran and a bridge between the capital and the northern and western regions, as well as Caucasus and European countries. Figures related to the traffic accidents in Qazvin province show that this province has a large share of road accidents due to the small geographical area in the country. The present study aimed to determine the influential factors in the survival of trauma victims until discharge from selected hospitals in Qazvin province during 2014-2018.

Materials \& Methods: This retrospective correlational study was conducted on 835 trauma patients using the data of Qazvin Emergency Center during 2014-2018. All the cases of the air transport of injured patients were included in the study due to the small number of cases. Among the cases of transferring trauma patients via the ground route, the subjects were selected via stratified random sampling with an equal volume for each year of the study period. Data were collected using an information registration form consisting of data on personal characteristics, trauma characteristics, pre-hospital and hospital emergency procedures, patientchr('39')s clinical condition upon arrival at the patientchr('39')s bedside, transfer mode, consciousness level at different times, and vital signs at different times. Data collection tools were the emergency center information questionnaire and the hospital records of trauma victims. Data analysis was performed in SPSS 16 using Chi-square, t-test, and regression analysis at the significance level of $\mathrm{P}<0.05$.

Results: Out of 835 trauma victims, 608 cases (72.8\%) were male, and 227 cases $(27.2 \%)$ were female. In terms of age distribution, the mean age of the injured subjects was $39 \pm 16.03$ years (range: 18-98 years). The trauma pattern was pervasive in 106 patients $(12.7 \%)$ and blunt in 729 patients (87.3\%). Among the subjects, 59 cases (7.1\%) died of trauma, of which 14 cases $(23.7 \%)$ had penetrating trauma and 45 cases $(76.3 \%)$ had blunt trauma. The mean body mass index of the trauma patients in the hospital was $25.88 \pm 4.44 \mathrm{~kg} / \mathrm{m}^{2}$. Underlying disease $(\mathrm{P}=0.03)$ and smoking habits $(\mathrm{P}=0.028)$ were significantly correlated with survival. The most common site of trauma was the limbs in 790 patients $(94.6 \%)$. The type of trauma was blunt in 729 patients $(87.3 \%)$ and 106 patients $(12.7 \%)$, and the most common cause of trauma in 602 cases $(72.1 \%)$ was vehicle accidents, while

1. Nursing Care Research Center, Critical care and emergency department, School of Nursing and Midwifery, Iran University of Medical Sciences, Tehran, Iran

2. MS in Emergency Nursing, School of Nursing and Midwifery, Iran University of Medical Sciences, Tehran, Iran

(Corresponding author) Tel: +989127827509 Email: cheginishayan89@gmail.com

${ }^{3}$. Biostatistics, Nursing Care Research Center, Iran University of Medical Sciences, Tehran, Iran

${ }^{4}$. Emergency Medicine Specialist, Qazvin University of Medical Sciences and Health Services, Qazvin, Iran
\end{abstract}


the least common causes were work-related accidents, explosion/lightning, and electric shocks $(\mathrm{n}=30 ; 3.6 \%)$. In addition, the mean severity of head, face, abdomen, upper limb, lower limb, and superficial anatomy injuries of the subjects was estimated at $22.66 \pm 13.64$, and the mean severity of head, face, abdomen, limbs, pelvis, and chest injuries of the subjects was $21.62 \pm 14.23$. The mean total duration of emergency services was one hour and 21 minutes (standard deviation: 33 minutes), and the mean duration of release operations was 25 minutes (standard deviation: 11 minutes). To investigate the influential factors in survival, a logistic regression model was used along with the inter-method reliability, and the variables affecting survival were analyzed by the regression model. According to the findings, the injury severity score (ISS; $\mathrm{P}=0.001$ ) was significant in the regression model. In other words, a one-unit increased in the ISS reduced the chance of survival in the injured by 0.86 . Furthermore, the chance of survival in the injured who had normal pupil and heart conditions was three and four times higher, respectively.

Conclusion: Proper and timely methods of diagnosis and treatment of trauma (especially the prevention of these injuries) are paramount. Due to the high prevalence of traffic accidents as the main cause of such injuries, cultural and social structures should be corrected in the field of driving and transportation improvement. Diagnosis of the severity of the injuries plays a key role in effective patient care and leads to reduced mortality and morbidity due to major trauma. Given the large number of road accidents, efforts must be made to develop the necessary care and protocols to prevent death following trauma in proportion to the severity of the patientchr('39')s injury. This requires the cooperation of various institutions, including the police, roads, and urban development.

\section{Keywords: Helicopter, Survival Rate, Trauma Severity, Pre-hospital Emergency}

\section{Conflict of Interest: No}

How to Cite: Najafi Ghezeljeh T, Chegini SH, Haghani SH, Namdar P. Influential Factors in the Survival Rate of Trauma Victims until Discharge from the Hospital. Iran Journal of Nursing. 2021; 33(128):67-83. 


\title{
عوامل مرتبط با ميزان بقاى مصدومان تروما تا زمان ترخيص از بيمار ستان در استان قزوين
}

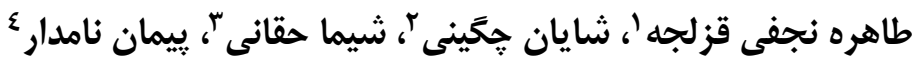

جكيده

زمينه و هدف: تروما يكى از مهمترين جالشهاى بهداشت عمومى جهان محسوب مىشود. خدمات اورزانس بيش بيمارستان نقش كليدى در ارائه

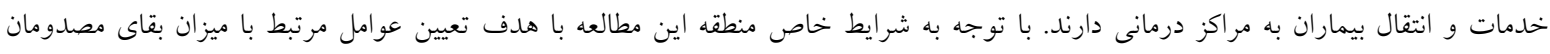

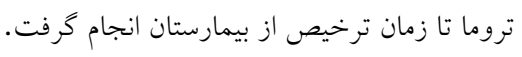

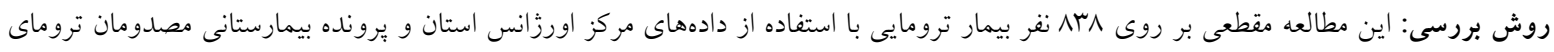

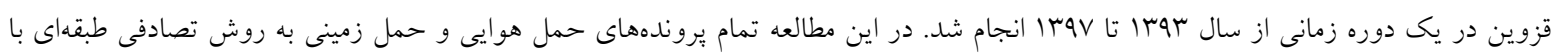

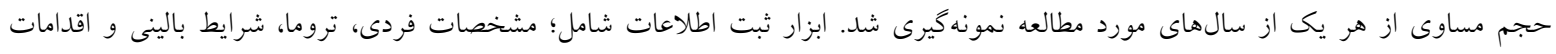

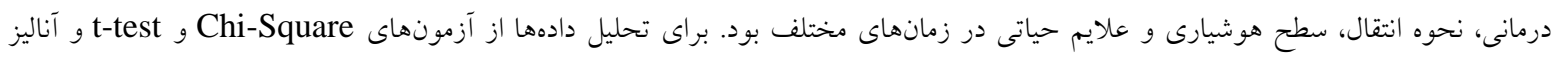

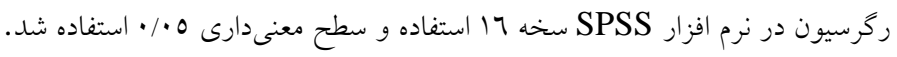

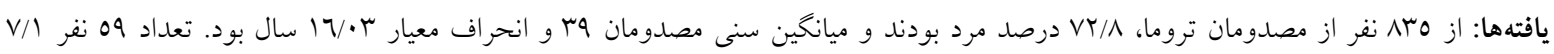

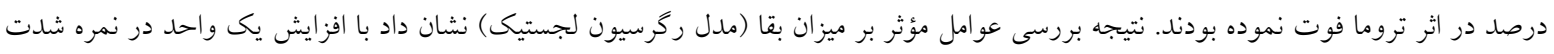

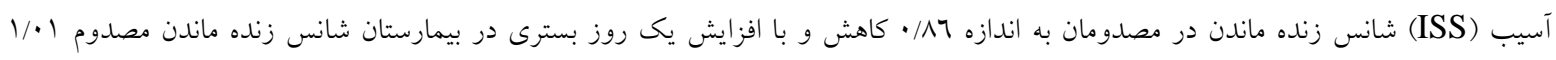
برابر بيشتر مىشود.

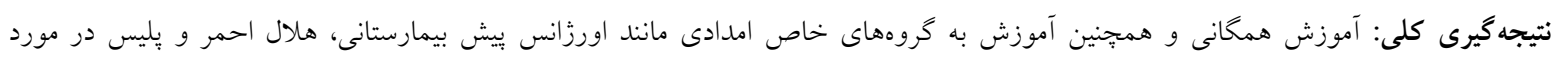

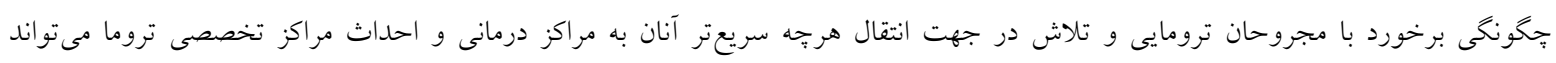

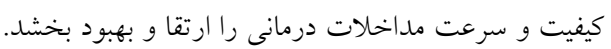

كليد وازهها: بالكرد، ميزان بقا، شدت تروما، اورزانس بيش بيمارستانى

$$
\text { تاريخ داريخ منافع: ندارد }
$$

'. مركز تحقيقات مراقبتهاى برستارى، تروه يرستارى مراقبت ويزه و اورزانس، دانشكده يرستارى و مامايى، دانشعًاه علوم يزشكى و خدمات بهداشتى درمانى ايران، تهران، ايران

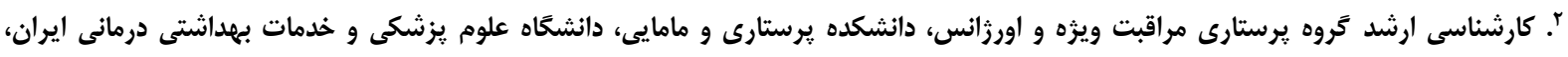

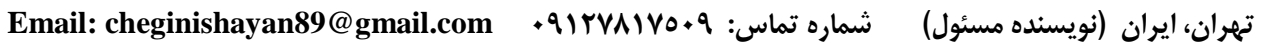

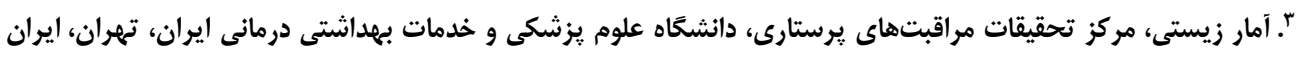

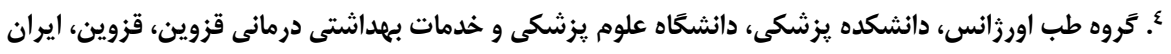


موفقيت در اين امر به ميزان زيادى بستخى به زمان بين

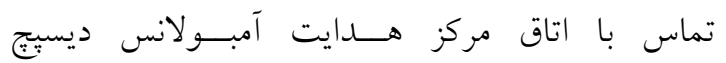
Dispatch تا زمان بِاسخدهى به افراد حاضر در صحنه،

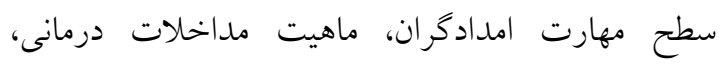

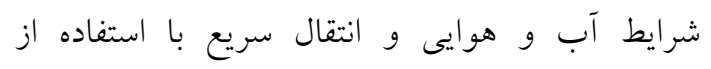

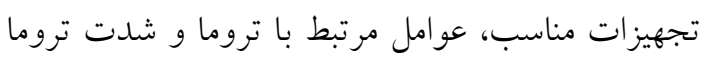

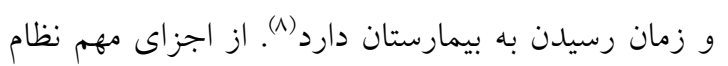

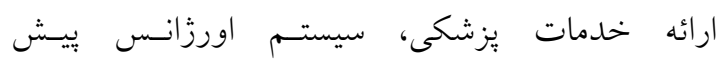

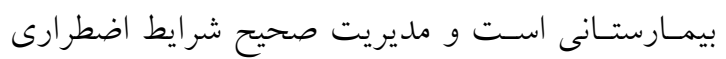
از مسائل مهم نظام سلامت است (9). در زمينه مطالعات انجام يافته در اورزانس بيش ميش بيمارستانى در يكى مطالعه مرور سيستماتيك، بهادرى و ودئه

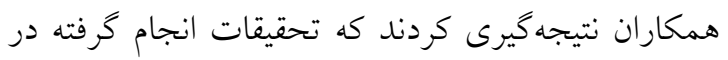
زمينه ارائه خدمات اورزانس بيش بيمارستانى در ايران محدود است (·). نتايج مطالعهاى ديخر در هلند نيز حاكى بئى

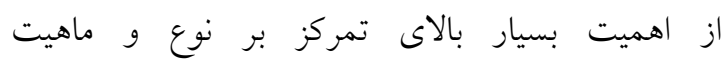

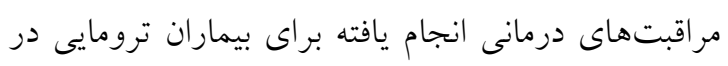

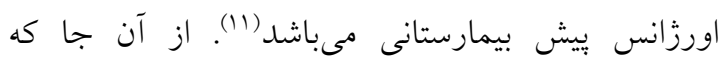

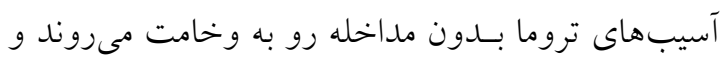

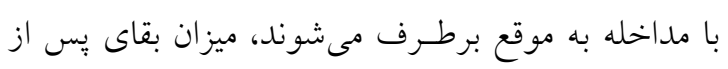

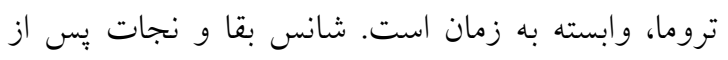

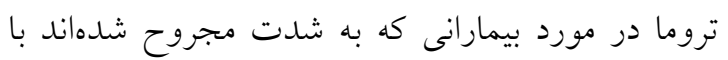

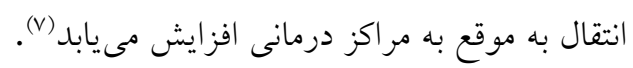
فوريتهاى يزشكى به مواردى كفته مىشود كه بيمار

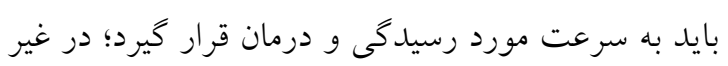

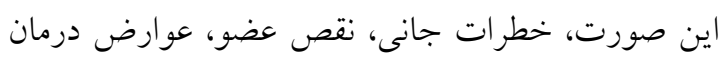

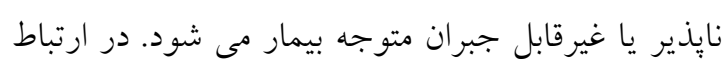

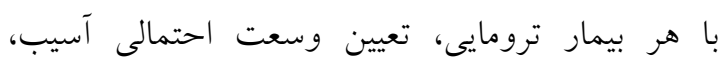

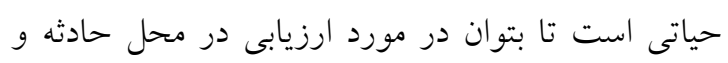

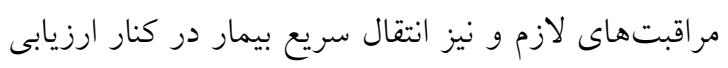

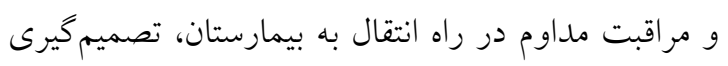
به موقع و درستى انجام كيرد. براى به انجام رساندن اين

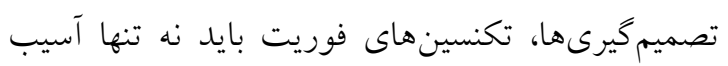

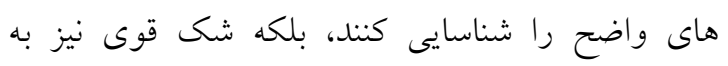

\section{مقدمه} تروما، صدمه و جراحت ناشى از نيروهاى خارجى است

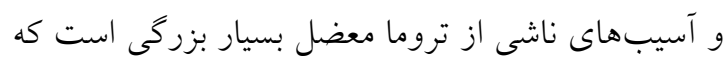

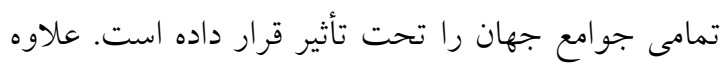

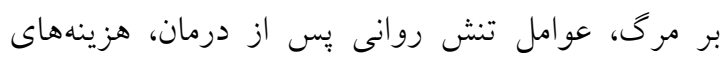

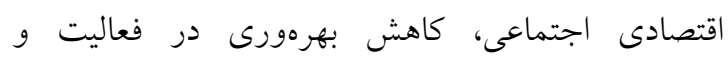

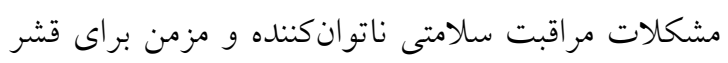
جوان و كارآمد را به جامعه تحميل مى كند (1). تروما، اصلىترين علت كاهش طول عمر و از دست دادن

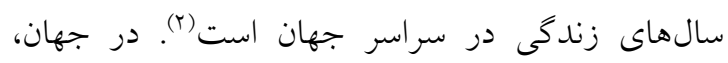

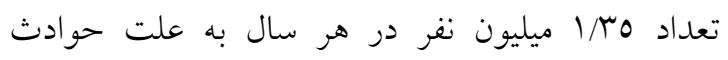

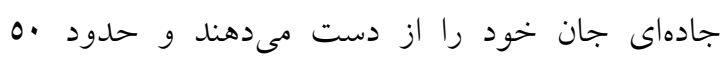
ميليون نفر از حوادث جادهاى آسيب مىبينند (r). آمار تصادفات جادهاى در ايران بيست برابر بيشتر از ميانخين

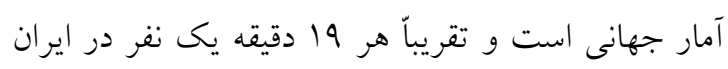
در تصادفات جادهاى جان خود را از دست مى دهد (ع).

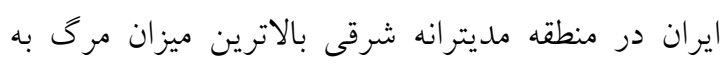

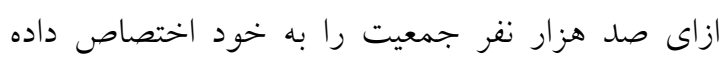

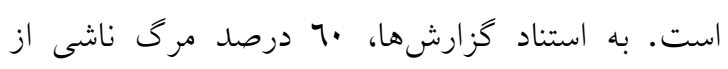

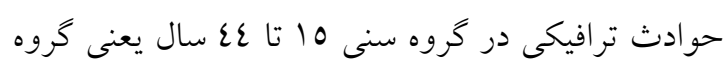
سنى فعال جامعه رخ مى دهد (0).

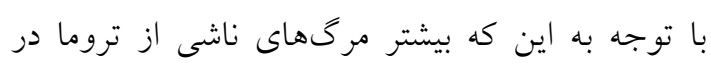

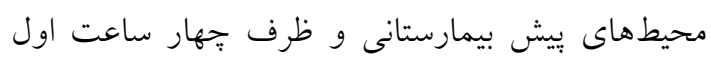

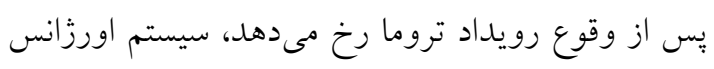

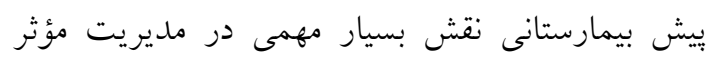

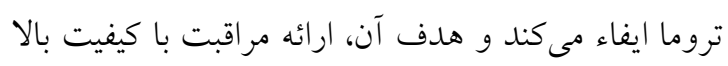
و كاهش آسيب و مرى در بيماران است (7). مهمترين

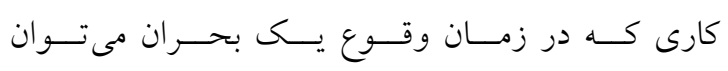

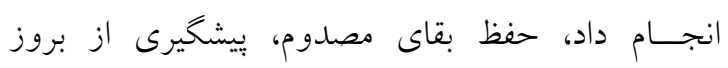

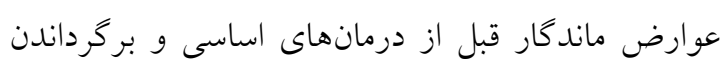

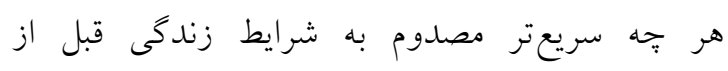

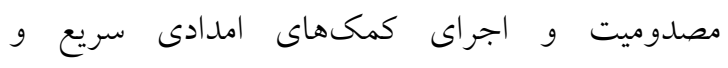
هوشمندانه است تا بتوان ميزان خسارات وارد شده رات تاك

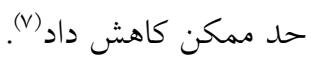


تروما بين دو نوع انتقال هوايى و زمينى وجود ندارد (1).

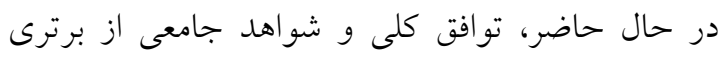

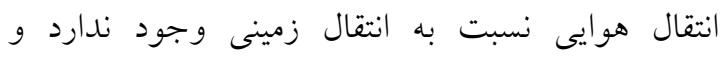

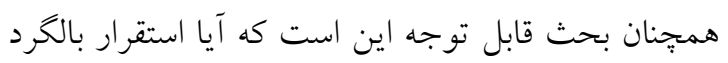
براى بقاى بيشتر بيماران تروما مؤثر است يا خير (19).

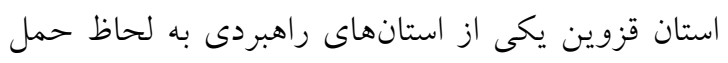

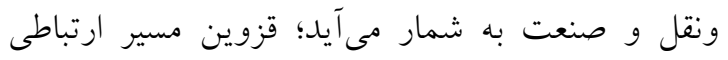

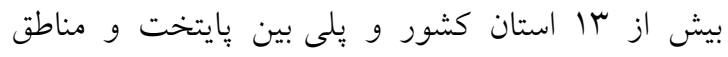

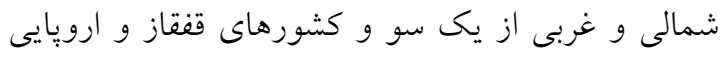

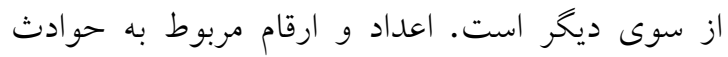
ترافيكى استان قزوين نشان مىدهد كه اين استان با توجه به وسعت جغرافيايى اندى در كشور، سهم فراوانى از

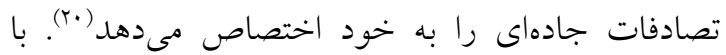
توجه به مطالب ياد شده و از آن جا كه شناخت عوامل مؤثر بر بقاى اين بيماران و كنترل آنها موفقيت بيشترى به به

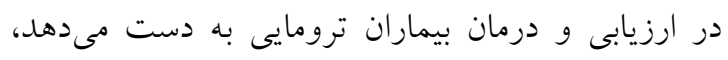

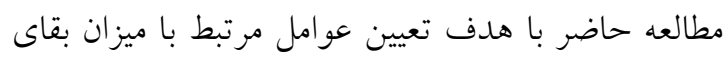
مصدومان تروما تا زمان ترخيص از بيمارستان انجام كرفته اشت.

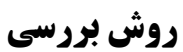

مطالعه حاضر يكى مطالعه كذشته نخر از نوع همبستخى

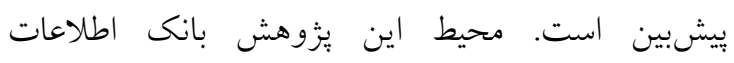

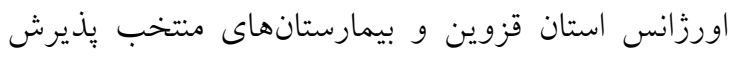

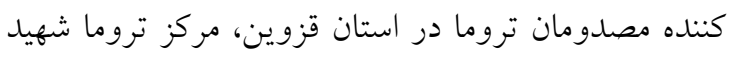

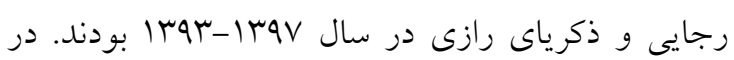
اين يُزوهش تمامى مصدومان تروماى داراى يرونده در

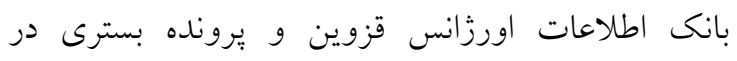
بيمارستانهاى منتخب استان قزوين در طى سالهاى

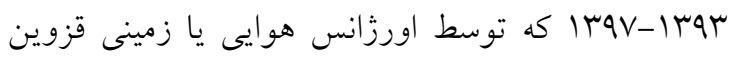
منتقل شده و داراى شرايط ورود به مطالعه بودند، جامعه يزوهش را تشكيل مى دادند. معيارهاى ورود عبارت بودند

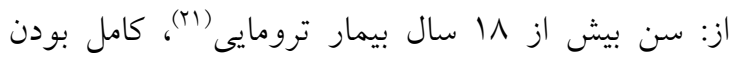

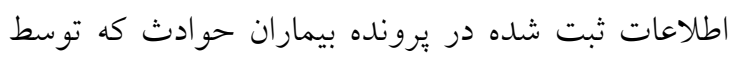
واحد اورزانس 110 استان قزوين انتقال يافته بودند.
صدمات ينهانى داشته باشند. فهم ساز و كار آسيب، جزء

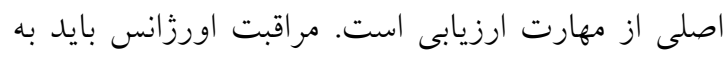
عنوان سيستم كامل با اجزاى مستقل درى شود. اين اجزا شامل مراقبت بيش بيمارستانى، حمل و نقل و هم:جنين

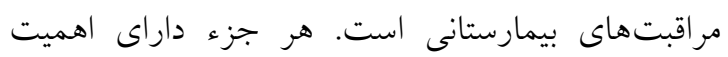

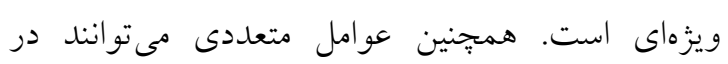

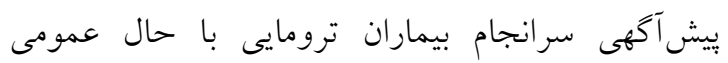

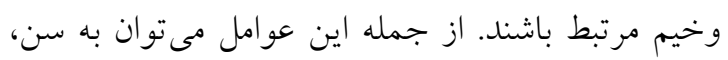

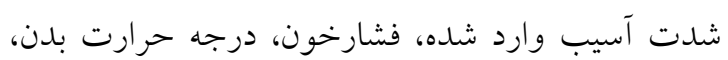
درجه كماى كلاسكو و برخى اندازههاى آزمايشكاهى

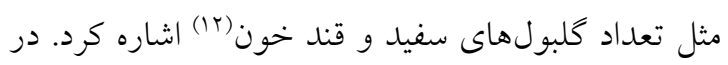
برخى مطالعات آسيب سر، افزايش سن و نمره شدت فن فئس

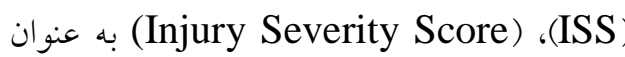

شاخص مستقل مرتبط با مرى گزارش شدهاند (عا،ـاء).

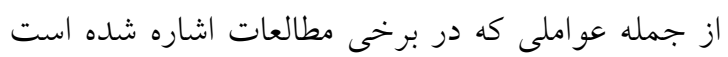

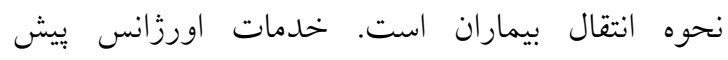
بيمارستانى توسط اورزانس زمينى و هوايى صورت

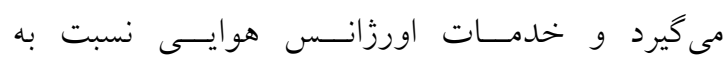

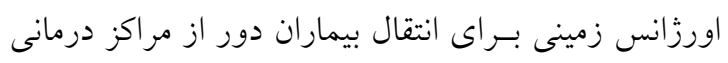

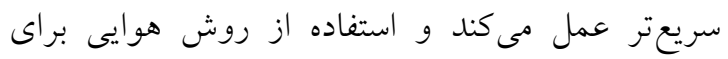

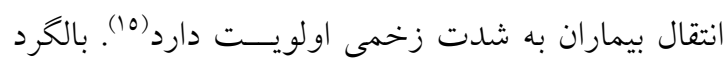

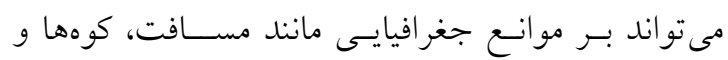

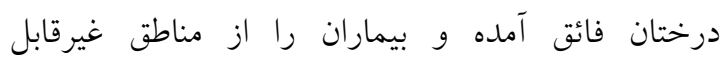

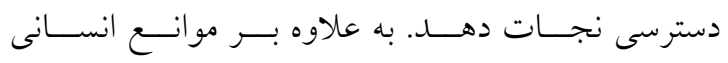

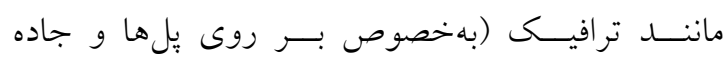

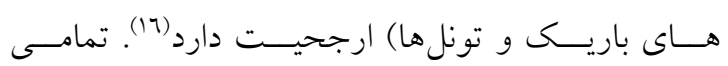

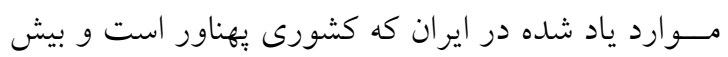

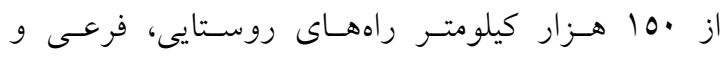

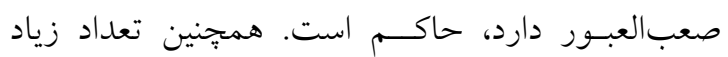

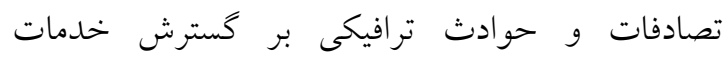
اورزانس هوايى صحه مى گذارد (v). برخى مطالعات نشان بران

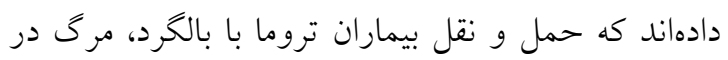

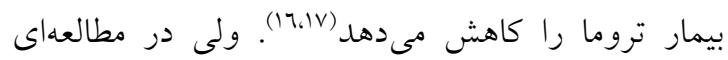
محققان گزارش كردند كه تفاوتى بين ميزان مرى بيماران 
اندازه مردمك، سمع و ريتم صداهاى ريه، سمع و ريتم

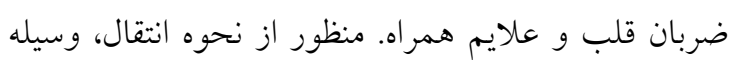
حمل بيمار از محل تروما تا مركز درمانى توسط اورزانس

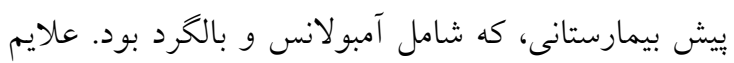
حياتى مورد بررسى شامل فشارخون، درجه حرارت بدن

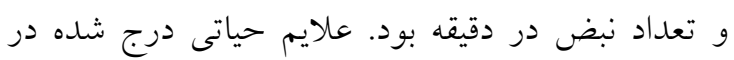
يرونده اورزانس و بيمارستان در زمانهاى رسيدن بر بالين

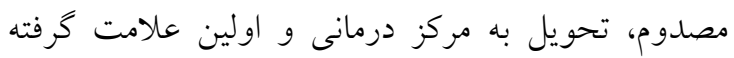
شده در بخش اورزانس، در فرم ثبت اطلاعات توسط

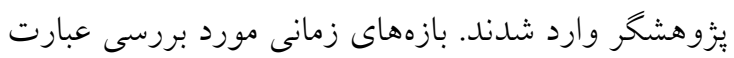

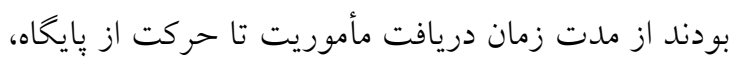
حركت از بايگاه تا رسيدن به محل فوريت، رسيدن به محل فوريت تا حركت از محل فوريت، مدت زمان عمليات رهاسازى، حركت از محل فوريت تا رسيدن به

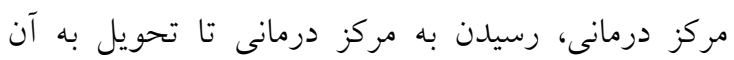

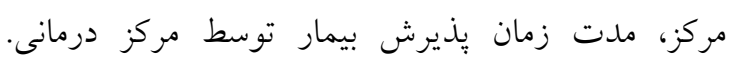

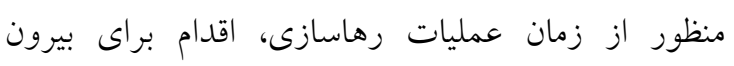
آوردن مصدوم از محل فوريت قبل يا در حضور تكنسين زمات رهان

روايى محتواى اين فرمها توسط پانل متخصصان متشكل

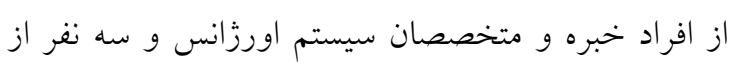
اعضاى هيئت علمى دانشكده يُرستارى و مامايى دانشگاه علوم يزشكى ايران بررسى شد.

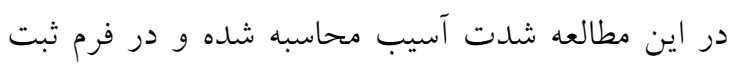
مىشد. در اين يُزوهش شدت آسيب، نمره حاصل از

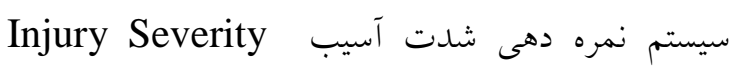
Score -ISS (Abbreviated Injury Scale) AIS قسمت سر، صورت، شكم، اندامهاى فوقانى و تحتانى و آناتومى سطحى تقسيم و بر اساس شدت تروما در منطقه

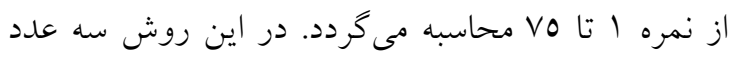

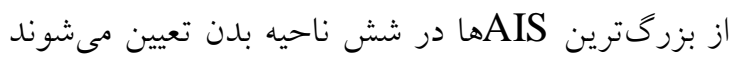

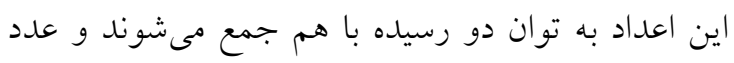
حاصل نمره شدت آسيب (ISS) ناميده مى شود. توضيح
براى تعيين حداقل حجم نمونه لازم به منظور برآورد

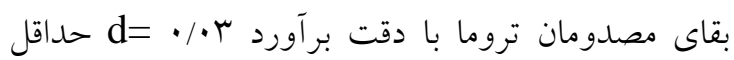

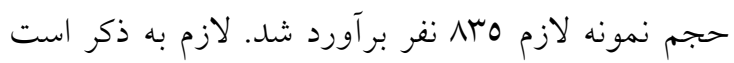

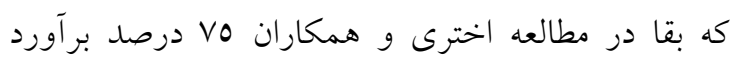

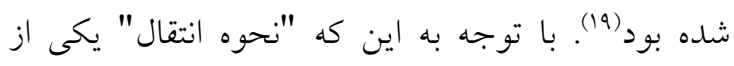

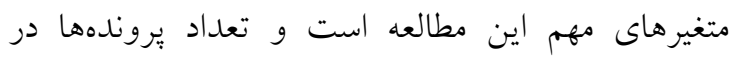
اورزانس زمينى تقريباً دو برابر هوايى است، نمونه كيرى به به إنه

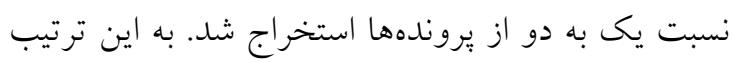

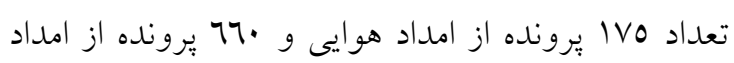
زمينى بهطور تصادفى انتخاب شد. در اين مطالعه تمام

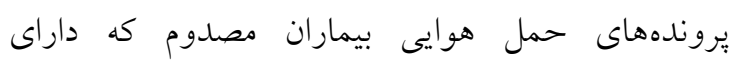
معيارهاى ورود به مطالعه بودند، به دليل تعداد كم موارد

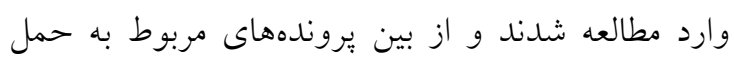
بيماران ترومايى به صورت زمينى به روش تصادفى طبقه

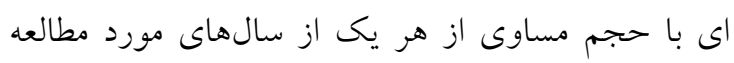

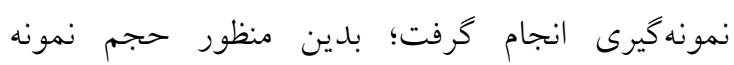

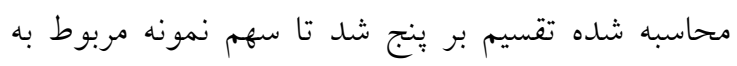
هر سال مشخص شود. ابزار جمع آورى اطلاعات فرم ثبت اطلاعات و شود شامل

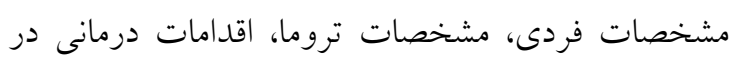
اورزانس ييش بيمارستانى و بيمارستان، شرايط بالينى درئي

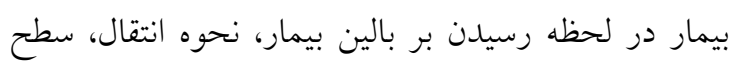

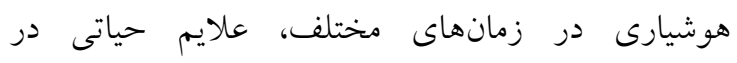
زمانهاى مختلف و زمانهاى مورد بررسى بود.

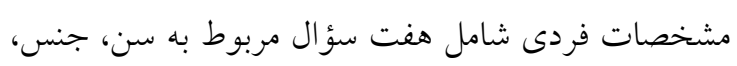
بيمارى همراه، سابقه مصرف سيخار و الكل، سابقه هنه

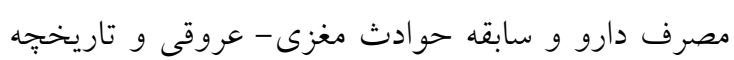
يزشكى بود. مشخصات تروما شامل نوع وسيله نقليه،

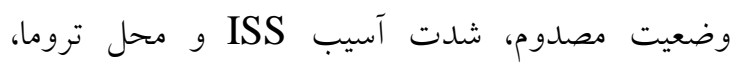
موقعيت جغرافيايى محل تروما، نوع ضايعه، نوع تروما

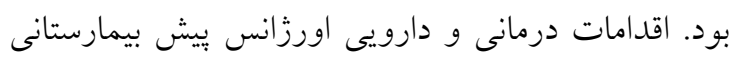
شامل: ساكشن، CPR بايه و يِيشرفته، پِانسمان و كنترل

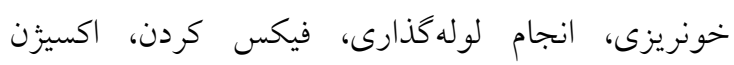

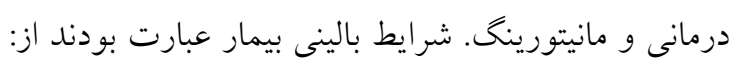




\section{يافتهها}

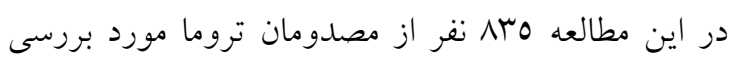

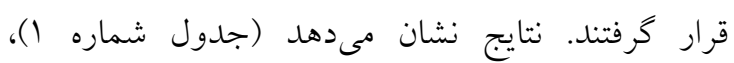

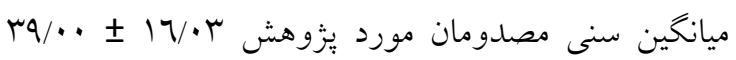

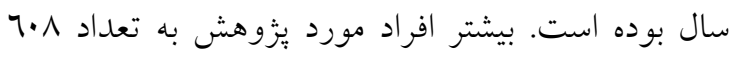

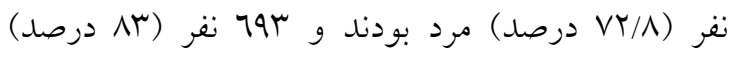

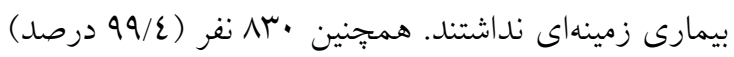

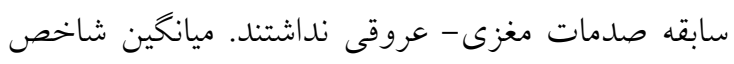

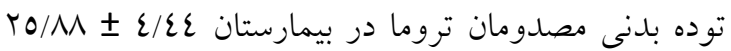

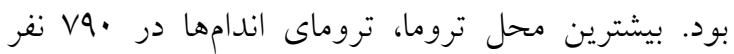

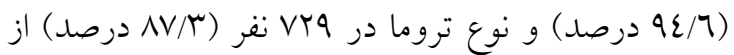

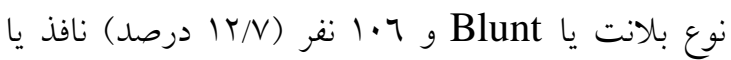
Penetrating آن مربوط به تصادفات وسايل نقليه و كمترين آن مربوط به ساير موارد شامل حوادث ناشى از كار، دارئ

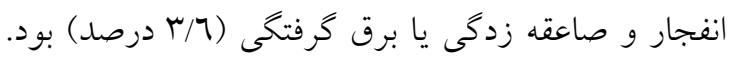

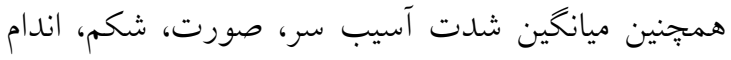

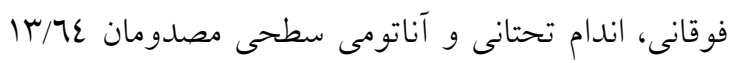

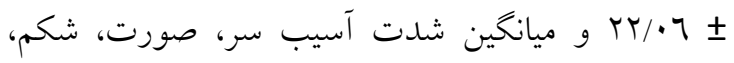

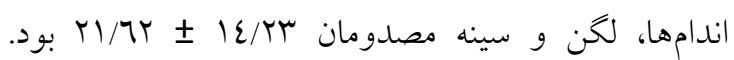

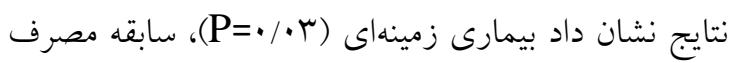

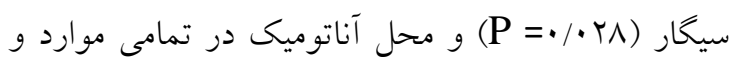

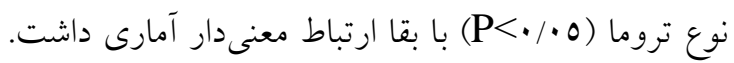
ميانكين ISS (سر، صورت، شكم، اندام فوقانى، اندام تحتانى و آناتومى سطحى) در مصدومان زنده (1/1)

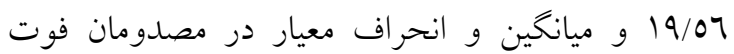

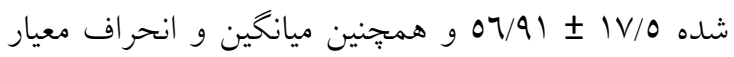
ISS

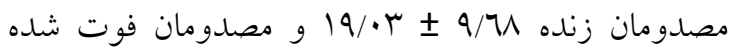

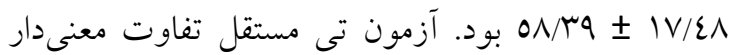
آمارى را در ISS (سر، صورت، شكم، اندام فوقانى، اندام

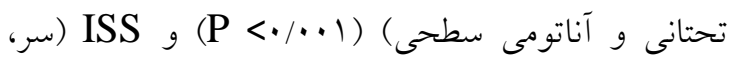

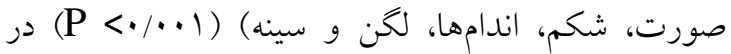
افراد فوت شده و بقا يافته نشان داد.
آنكه اگر نمره يك ارگان شش باشد (غير قابل حيات)

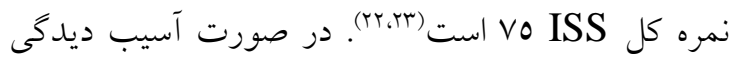
عضله و بر اساس ميزان از كارافتادكى آناتوميك و عملكردى آن، نمره ا 1 تا 7 و جّنانجه سه عضو يا بيشتر صدمه ديده باشد، بالاترين نمره از سه عضو محاسبه

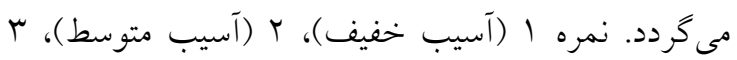
(شديد ولى بدون خطر مرگ)، ع (شديد با خطر مرگ)، (بحرانى) و 7 (كشنده) بر اساس قضاوت بالينى توسط تكنسين دوره ديله اورزانس نسبت داده مىشود. هر كدام از اين اعداد يك AIS ناميده مىشود(ع؟r.). بعد از گرفتن مجوز از كميته اخلاق دانشخاه علوم يزشكى ايران (IR.IUMS.REC.1398.393)، دريافت معرفى نامه از دانشخاه و كسب مجوز اجراى يزوهش از دانشخاه علوم يزشكى قزوين با مراجعه به مركز اورزانس قزوين و

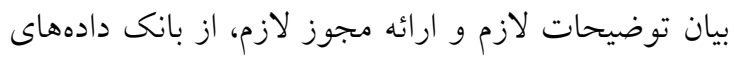
مركز اورزانس و يرونده بيمارستانها دادهها استخراج شد. ملاحظات اخلاقى اين يزوهش شامل كسب اجازه ورود به محيط يزّوهش از مسئولان مراكز، رعايت كامل اصول اخلاقى و امانتدارى در استفاده از ساير تحقيقات و منابع توسط يزوهشخر، حفظ محرمانه بودن اطلاعات كسب شده، بدون نام بودن فرم مشخصات فردى و استفاده از اطلاعات آن صرفاً در اجراى يزّوهش، انتشار دقيق و واقعى نتايج، در اختيار قرار دادن نتايج بيزوهش به مسئولان محيط يزّوهش و رعايت صداقت در نمونه گيرى، جمع آورى و تحليل دادهها بود. بس از تكميل فرمها، جهت تحليل دادهها از نرم افزار

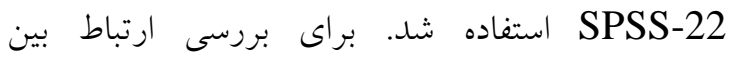
متغيرهاى كيفى از آزمون كاىدو و در صورت نداشتن شرايط كاى دو از آزمون دقيق فيشر و براى مقايسه

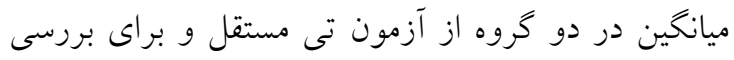
تأثير همزمان كليه متغيرهاى مرتبط با نتيجه تروما از تحليل ركرسيون لجستيك استفاده شد و سطح معنى دارى كمتر از 0 • • لحاظ كرديل. 
جدول شماره ا: ميزان بقاى مصدومان مورد يزوهش برحسب مشخصات فردى و تروما سال 9V-9

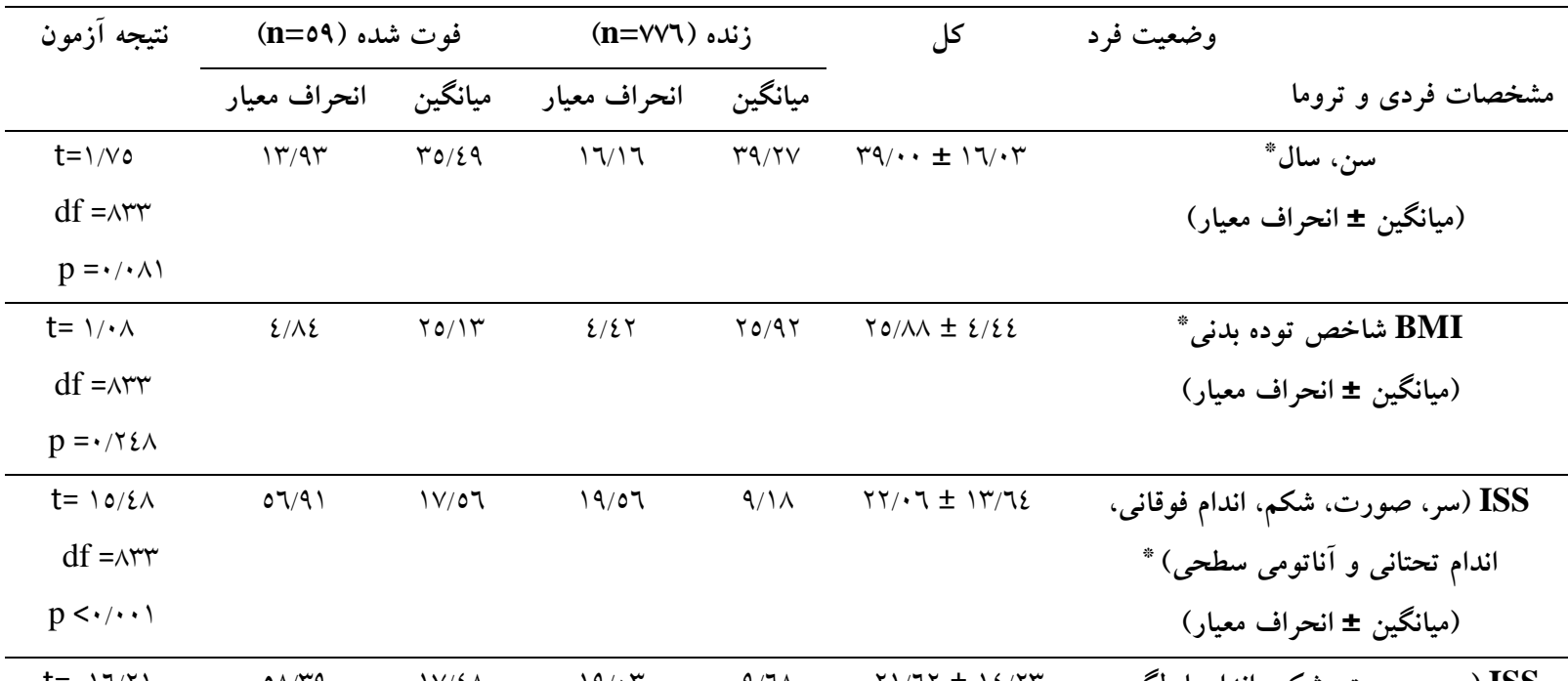

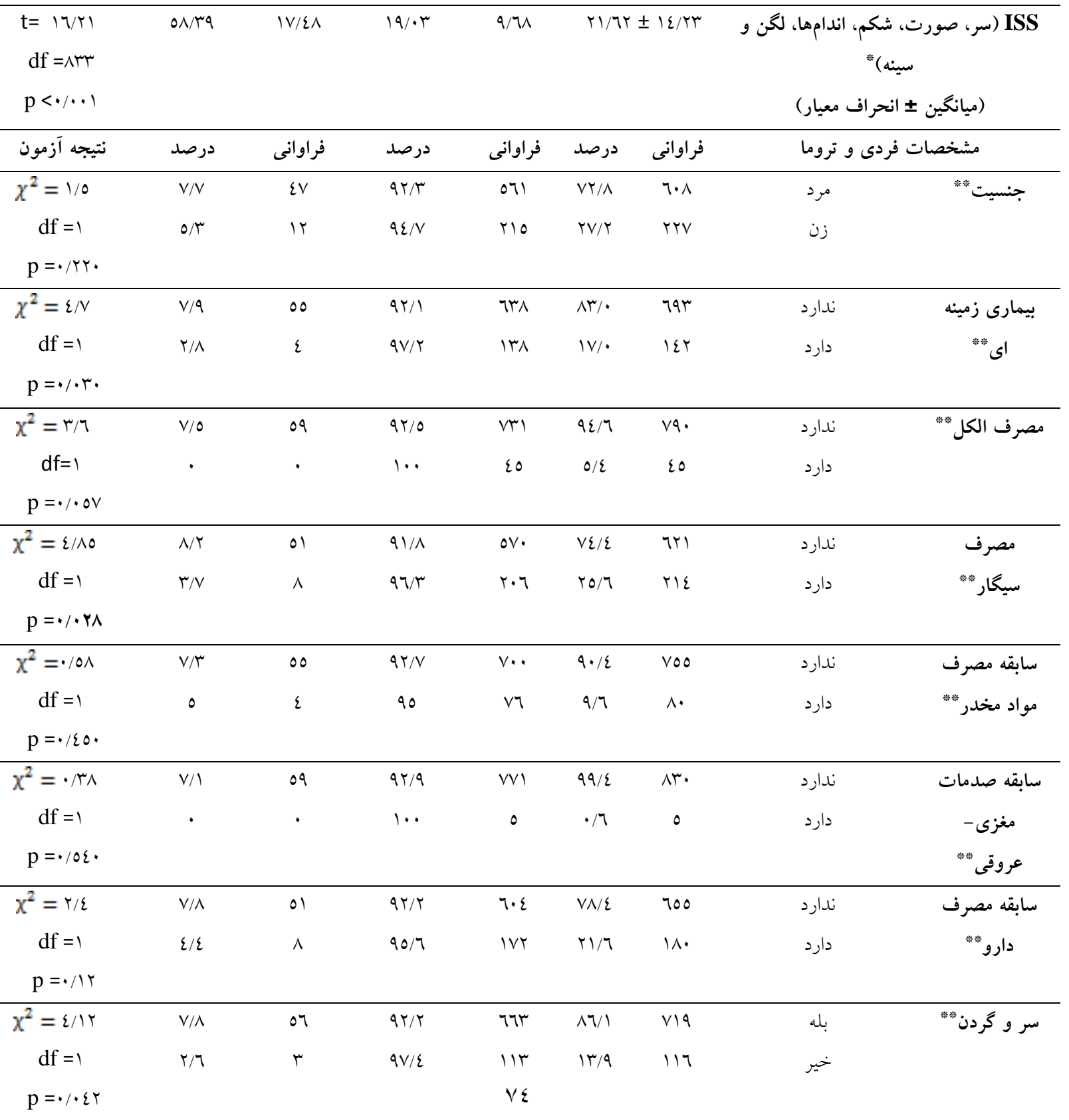




\begin{tabular}{|c|c|c|c|c|c|c|c|c|}
\hline $\begin{array}{c}X^{2}=r / \wedge \varepsilon \\
d f=1 \\
p=\cdot / \cdot 9 r\end{array}$ & $\begin{array}{l}T / V \\
1 \pi / r\end{array}$ & 7 & $\begin{array}{l}q \pi / r \\
\Lambda T / V\end{array}$ & $\begin{array}{l}v r v \\
r q\end{array}$ & $\begin{array}{l}9 \varepsilon / 7 \\
0 / \varepsilon\end{array}$ & $\begin{array}{l}\text { va. } \\
\text { so }\end{array}$ & خير & اندامها"**" \\
\hline $\begin{array}{c}x^{2}=\mu \mu / \cdots \\
\text { df }=1 \\
p<\cdot / \cdots 1\end{array}$ & $\begin{array}{l}1 \Gamma / T \\
r / \Lambda\end{array}$ & ¿o & $\begin{array}{l}\Lambda T / \Lambda \\
Q V / r\end{array}$ & $\begin{array}{l}r 97 \\
\{\vee 9\end{array}$ & $\begin{array}{l}21 \\
09\end{array}$ & $\begin{array}{l}r \varepsilon r \\
\sum q r\end{array}$ & خله & توراكس*"* \\
\hline $\begin{array}{c}x^{2}=\varepsilon \cdot / \cdot 1 \\
\text { df }=1 \\
p<\cdot / \cdot \cdot 1\end{array}$ & $\begin{array}{l}r Y / \mathcal{L} \\
0 / \cdot\end{array}$ & $\begin{array}{l}r T \\
\text { rV }\end{array}$ & $\begin{array}{l}V V / T \\
90 / \cdot\end{array}$ & $\begin{array}{l}v_{7} \\
v_{n}\end{array}$ & $\begin{array}{l}11 / 9 \\
11 / 1\end{array}$ & $\begin{array}{l}99 \\
V \pi r\end{array}$ & خير & شكم" \\
\hline $\begin{array}{c}x^{2}=0 / 99 \\
d f=1 \\
p=\cdot / \cdot 1 \varepsilon\end{array}$ & $\begin{array}{l}1 . / 0 \\
0 / V\end{array}$ & $\begin{array}{l}r_{0} \\
r \varepsilon\end{array}$ & $\begin{array}{l}19 / 0 \\
q \varepsilon / \mu\end{array}$ & rוץ & $\begin{array}{l}\text { YN/O } \\
V I / T\end{array}$ & $\begin{array}{l}\text { rHA } \\
\text { OQV }\end{array}$ & خير & ستون فقرات" \\
\hline $\begin{array}{c}x^{2}=7 / 9 \vee \\
d f=1 \\
p=\cdot / \cdot \wedge\end{array}$ & $\begin{array}{l}1 \pi / T \\
T / r\end{array}$ & $\begin{array}{l}1 \varepsilon \\
\varepsilon 0\end{array}$ & $\begin{array}{l}\Lambda \tau / \Lambda \\
q \pi / \Lambda\end{array}$ & $\begin{array}{l}q Y \\
T \wedge \varepsilon\end{array}$ & $\begin{array}{l}I T / V \\
N V / r\end{array}$ & $\begin{array}{l}1.7 \\
\text { VTa }\end{array}$ & بافن & نوع تروما:" \\
\hline $\mathrm{p}=\cdot / 17 \mathrm{r}$ & $\begin{array}{l}V / 1 \\
7 / 9 \\
\varepsilon / 1 \\
17 / V\end{array}$ & $\varepsilon r$ & $\begin{array}{l}9 r / 9 \\
9 \pi / 1 \\
90 / T \\
1 \% / r\end{array}$ & $\begin{array}{l}009 \\
0 \varepsilon \\
140 \\
\text { ro }\end{array}$ & $\begin{array}{l}V T / 1 \\
T / 9 \\
I V / \varepsilon \\
r / 7\end{array}$ & $\begin{array}{l}7 . r \\
01 \\
120 \\
r .\end{array}$ & تصادفات وسايل نقليه & علت تروما خ \\
\hline
\end{tabular}

اندام، رگگیرى و سرم درمانى با بقا ارتباط معنىدار

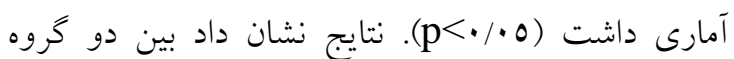
انتقال زمينى و هوايى از نظر بقاى مصدومان تفاوت معنى

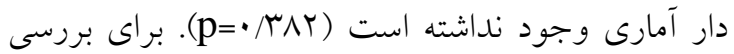
ارتباط بقا با اقدامات درمانى انجام شده توسط اورزانس بيش بيمارستانى از مدل رگرسيون لجستيك به روش فوروارد استفاده شد كه متغيرهاى حمايت تنفسى

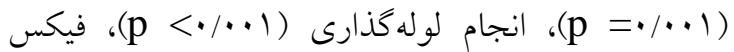
كامل (1)

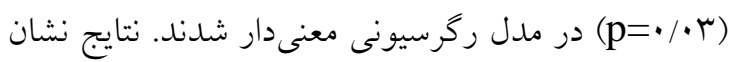
دهنده آن است كه شانس زنده ماندن در بيمارانى كه حمايت تنفسى، انجام لوله گذارى، فيكس كامل و سرم

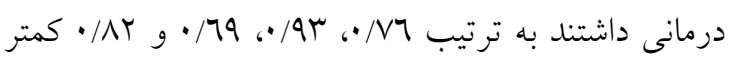
بود. همجنين شانس زنده ماندن در بيمارانى كه رگ گيرى

$$
\text { داشتند ع ا برابر بيشتر بود. }
$$

براى بررسى ارتباط ميزان بقا با مشخصات تروما و ISS مصدومان از مدل رگرسيون لجستيك به روش فوروارد استفاده شد كه متغيرهاى محل تروما سر و كردن

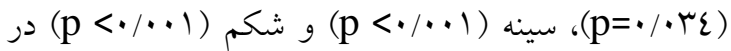
مدل رگرسيونى معنىدار شدند. نتايج نشاندهنده آن است كه شانس زنده ماندن در بيمارانى كه محل آسيب در سر و كردن، سينه و شكم بود به ترتيب به اندازه س ب/ •، V7/ و ISS • • كاهش مى يابد. همجنين ملاحظه مى شود كه (سر، صورت، شكم، اندامها، لكن و سينه) نيز در مدل رگرسيونى معنى دار شد (1) (p p)، به عبارتى با افزايش يك واحد در ISS شانس زنده ماندن در مصدومين به اندازه 117/ • كاهش مىيافت. بر اساس نتايج (جدول شماره r) اقدامات قبل و حين انتقال مصدومان در موارد ساكشن، حمايت تنفسى، انجام لوله گذارى، دارو درمانى، احياى قلبى ريوى، كنترل

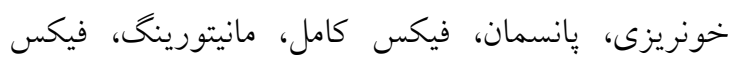




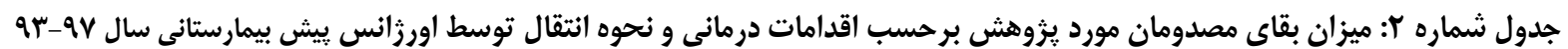

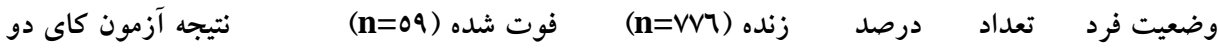

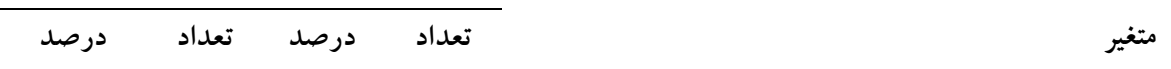

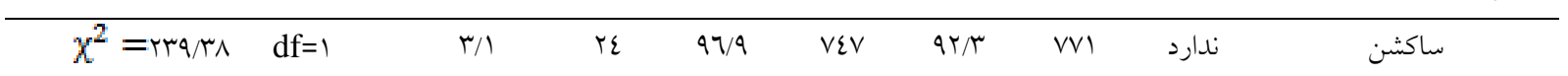

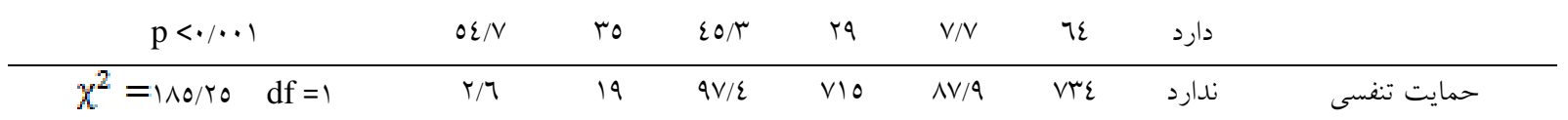

\begin{tabular}{|c|c|c|c|c|c|c|c|c|}
\hline $\mathrm{p}<\bullet / \cdots)$ & $r q / 7$ & $\varepsilon \cdot$ & $7 \cdot / \varepsilon$ & 71 & $\mid r / 1$ & 1.1 & دارد & \\
\hline$x^{2}=r \cdots / 1 \quad \mathrm{df}=1$ & $r / 0$ & rA & $97 / 0$ & V70 & 90 & var & 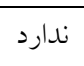 & انجام لوله گذارى \\
\hline $\mathrm{p}<\bullet / \cdots)$ & $V r / \Lambda$ & $\mu$ & $r T / r$ & 11 & $0 /$. & $\varepsilon r$ & دارد & \\
\hline$X^{2}=1 \mu r / \varepsilon \quad$ df $=1$ & $\varepsilon / \mu$ & r & $90 / \mathrm{V}$ & Vथr & $9 r / 9$ & VVI & ن ندارد & دارو درمانى \\
\hline
\end{tabular}

\begin{tabular}{|c|c|c|c|c|c|c|c|c|}
\hline $\mathrm{p}<\cdot / \cdots 1$ & $\varepsilon \varepsilon / 1$ & r & $00 / 9$ & r & $\mathrm{V} / \mathrm{I}$ & 09 & دارد & \\
\hline$X^{2}=1 \cdot r / 1 \quad \mathrm{df}=1$ & $0 / 9$ & $\varepsilon \wedge$ & $9 \varepsilon / 1$ & VVT & $9 \Lambda / r$ & $\Delta r$. & ن ندارد & احياى قلبى ريوى \\
\hline
\end{tabular}

\begin{tabular}{|c|c|c|c|c|c|c|c|c|}
\hline $\mathrm{p}<\bullet / \cdots$ & $V \pi / \mu$ & 11 & $r T / V$ & $\varepsilon$ & $1 / 1$ & 10 & دارد & \\
\hline$x^{2}=7 / 7 . \quad$ df $=1$ & $r / r$ & V & $97 / 1$ & $r \cdot 9$ & $r o / 9$ & Y17 & 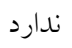 & كنترل خونريزى \\
\hline
\end{tabular}

\begin{tabular}{|c|c|c|c|c|c|c|c|c|}
\hline$p=\cdot / \cdot r V$ & $\Lambda / \varepsilon$ & Or & $91 / 7$ & $07 \mathrm{~V}$ & $V \varepsilon / l$ & 719 & دارد & \\
\hline$X^{2}=0 / 90 \quad$ df $=1$ & $\mu / \mu$ & v & $97 / \mathrm{V}$ & $r \cdot r$ & ro/1 & rl. & 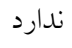 & يانسمان \\
\hline
\end{tabular}

\begin{tabular}{|c|c|c|c|c|c|c|c|c|}
\hline $\mathrm{p}=\cdot / \cdot 10$ & $\Lambda / 1$ & Or & $V \pi / \Lambda$ & ovr & $\vee \varepsilon / q$ & Tro & دارد & \\
\hline$X^{2}=\varepsilon \cdot / \cdot 1 \quad$ df $=1$ & $1 / 1$ & $\wedge$ & $9 \Lambda / r$ & $\varepsilon r$ & $\Delta r / T$ & $\varepsilon \varepsilon \varepsilon$ & 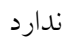 & فيكس كامل \\
\hline
\end{tabular}

\begin{tabular}{|c|c|c|c|c|c|c|c|c|}
\hline $\mathrm{p}<\bullet / \cdots+1$ & $1 \% /$ & 01 & $\wedge \mathrm{V} / \cdot$ & $r \varepsilon$. & $\varepsilon \tau / \Lambda$ & ral & دارد & \\
\hline$x^{2}=.1 \cdot 0 \cdot \quad$ df $=1$ & $\mathrm{~V} / \mathrm{\Lambda}$ & $\varepsilon$ & $9 T / r$ & $\varepsilon V$ & $7 / 1$ & 01 & ن ندارد & اكسيزن درمانى \\
\hline $\mathrm{p}=\cdot / \wedge r \mu$ & $\mathrm{V} / \cdot$ & 00 & $9 \pi / \cdot$ & VTq & $9 \pi / 9$ & $\vee \wedge \varepsilon$ & دارد & \\
\hline$X^{2}=1 \wedge / 1 \wedge \quad$ df $=1$ & $r / 9$ & 19 & $97 / 1$ & $\varepsilon v$. & $0 \Lambda / 7$ & $\varepsilon \wedge 9$ & ن ندارد & مانيتورينگ \\
\hline $\mathrm{p}<\bullet / \cdots+$ & $11 / 7$ & $\varepsilon$. & $\Lambda N / \varepsilon$ & $\mu \cdot \tau$ & $\varepsilon 1 / \varepsilon$ & $r \varepsilon\urcorner$ & دارد & \\
\hline$\chi^{2}=. / I V \varepsilon \quad$ df $=1$ & $V / r$ & 01 & $9 Y / \Lambda$ & 700 & $\wedge \varepsilon / 7$ & $v \cdot 7$ & 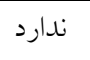 & فيكس كردن \\
\hline $\mathrm{p}=\cdot / 7 \mathrm{VV}$ & $T / r$ & $\wedge$ & $9 \pi / \Lambda$ & $|r|$ & $10 / 2$ & 119 & دارد & \\
\hline$\chi^{2}=\cdot / \varepsilon r 7 \quad \mathrm{df}=1$ & $v / \mu$ & 01 & $9 Y / V$ & $7 \varepsilon 0$ & $\Lambda \mu / \varepsilon$ & 797 & 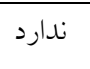 & فيكس ستون فقرات \\
\hline$p=\cdot 10 \cdot 9$ & $0 / 1$ & $\wedge$ & $9 \varepsilon / \Gamma$ & $|r|$ & $17 / 7$ & 149 & دارد & \\
\hline$\chi^{2}=$ v/or $\quad \mathrm{df}=1$ & $\Lambda / 7$ & 01 & $91 / \varepsilon$ & or. & $v \cdot / \Lambda$ & 091 & 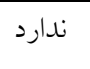 & فيكس اندام \\
\hline $\mathrm{p}=\cdot / \cdot \cdot \mathrm{r}$ & $\mu / \mu$ & $\wedge$ & $97 / \mathrm{V}$ & Trt & $r q / r$ & $r \varepsilon \varepsilon$ & دارد & \\
\hline$X^{2}=1 r / \cdot r \quad$ df $=1$ & TV/A & 0 & $V T / r$ & $1 r$ & $r / r$ & 11 & 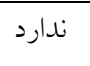 & رگ گيرى \\
\hline $\mathrm{p}=\cdot / \cdot \cdot 1$ & $7 / 7$ & or & $9 \pi / \varepsilon$ & vרr & $9 V / \Lambda$ & NIV & دارد & \\
\hline$x^{2}=1 \wedge / \mu q \quad \mathrm{df}=1$ & $1 / 0$ & $\varepsilon$ & $91 / 0$ & rar & $r 1 / 9$ & rา7 & 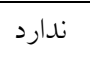 & سرم درمانى \\
\hline $\mathrm{p}<\bullet / \bullet \cdot$ & $9 / \mathrm{V}$ & 00 & $q \cdot / r$ & $01 \varepsilon$ & $W / 1$ & 079 & دارد & \\
\hline$\left.\chi^{2}=\cdot N\right\urcorner \varepsilon \quad \mathrm{df}=1$ & $7 / V$ & $\varepsilon \varepsilon$ & $9 \pi / r$ & 717 & Vq & 77. & 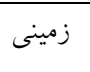 & نحوه انتقال \\
\hline $\mathrm{p}=\cdot / \Gamma \Lambda r$ & $\Lambda / 7$ & 10 & $91 / 2$ & 17. & YI & IVo & هوايى & \\
\hline
\end{tabular}


است به ازاى يك واحد افزايش در GCS شانس زنده ماندن در بيماران 1/ برابر بيشتر مىشود (جدول شماره

نتايج آزمون تى مستقل در اولين اندازه گيرى در بيمارستان (جدول شماره r) نشان داد ميانخين GCS، فشار خون سيستول و دياستول، قند خون، دماى بدن و

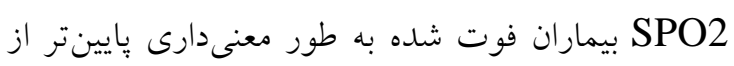

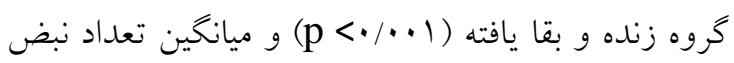

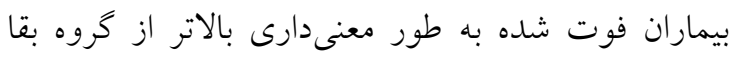

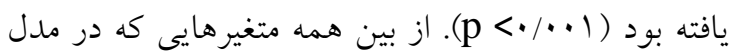

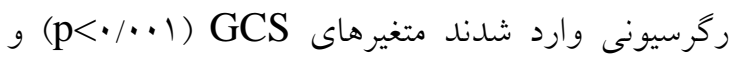
(p=•/r) SPO2 است كه به ازاى يك واحد افزايش در GCS و SPO2

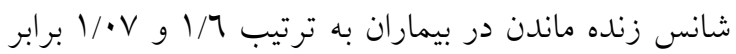

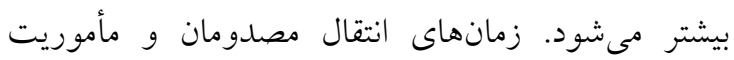

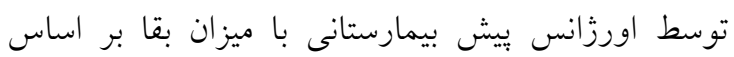

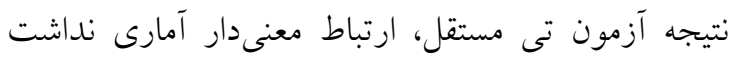

$(\mathrm{p}>\cdot / \cdot 0)$
براى بررسى ارتباط بقا با وضعيت بالينى در لحظه رسيدن

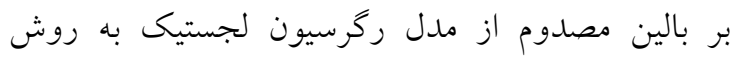

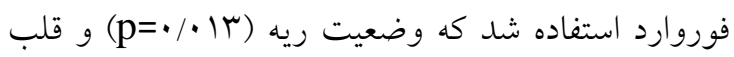
(p =•/×1)

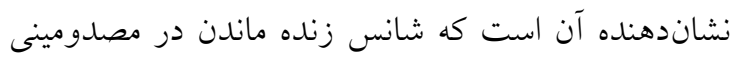
كه وضعيت ريه و قلب طبيعى داشتند به ترتيب جهار و و هشت برابر بيشتر است. همجنين نتايج نشان مىدهد كه وضعيت مردمكها، قلب و ريه مصدومان در لحظه

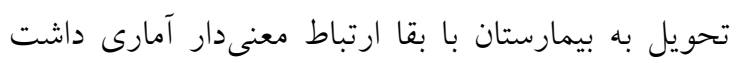

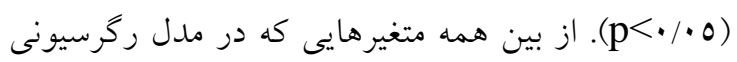

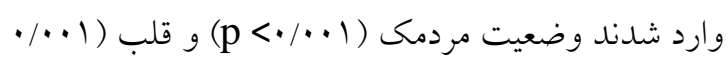

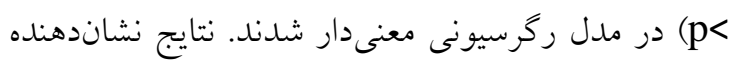

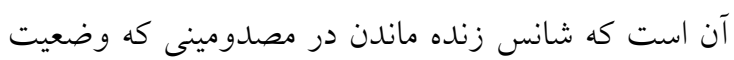

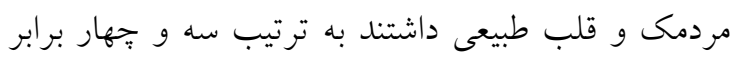
بيشتر است. بر اساس نتايج آزمون تى مستقل (جدول شماره ب)، در

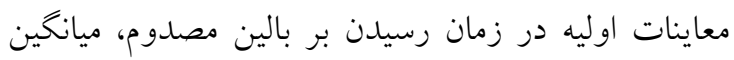
نمره مقياس كماى كاسكو GCS، فشار خون سيستول و

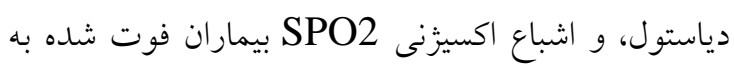

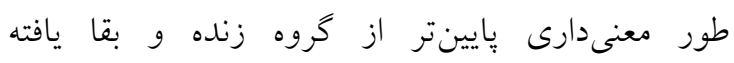

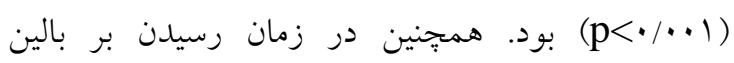

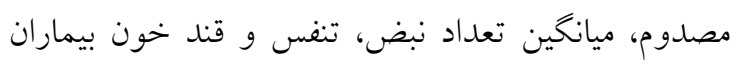
فوت شده به طور معنى دارى بالاتر از خروه بقا يافته بود.

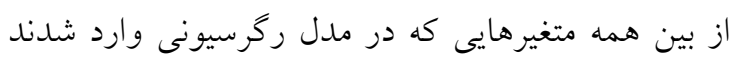

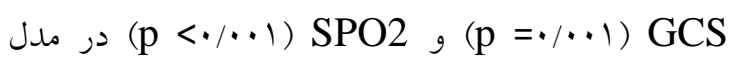
ركرسيونى معنى دار شدند. نتايج نشاندهنده آن است كه به ازاى يك واحد افزايش در GCS و SPO2 شنانس

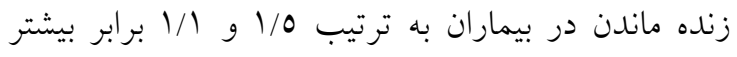

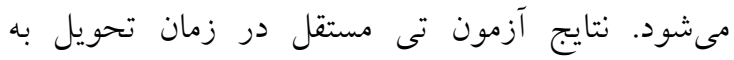
بيمارستان، نشان داد ميانخين GCS، فشار خون سيستول

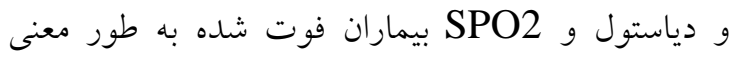
دارى بايينتر از گروه بقا يافته بود. از بين همه متغيرهايى

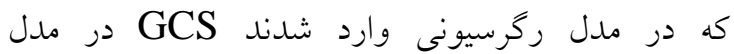

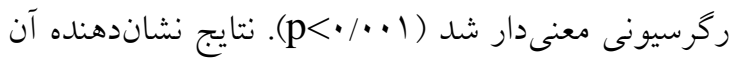




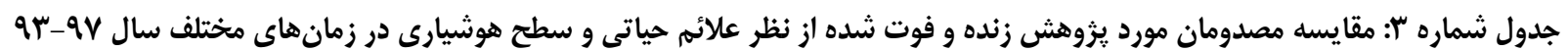

\begin{tabular}{|c|c|c|c|c|c|c|c|c|c|c|c|c|c|c|c|}
\hline \multicolumn{5}{|c|}{ اولين اندازه گيرى در بخش اورزانس } & \multicolumn{5}{|c|}{ زمان تحويل به بيمارستان } & \multicolumn{5}{|c|}{ زمان رسيدن بر بالين مصدوم } & \multirow{3}{*}{ متغييرها } \\
\hline \multirow[t]{2}{*}{ 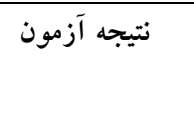 } & \multicolumn{2}{|c|}{ فوت شده (n=09) } & \multicolumn{2}{|c|}{ زنده (n=VVI) } & \multirow[t]{2}{*}{ 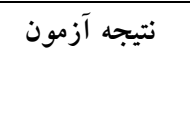 } & \multicolumn{2}{|c|}{ فوت شده (n=09) } & \multicolumn{2}{|c|}{ زنده (n=VV7) } & \multirow[t]{2}{*}{ 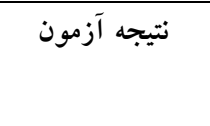 } & \multicolumn{2}{|c|}{ فوت شده (n=09) } & \multicolumn{2}{|c|}{ زنده (n=VV7) } & \\
\hline & انحر اف معيار & ميانگين & انحراف معيار & ميانخين & & انحرافمعيار & ميانخين & انحرافمعيار & ميانخين & & انحراف معيار & ميانخين & انحر اف معيار & ميانگين & \\
\hline $\begin{array}{l}t=\mid 1 / 71 \\
d f=\wedge r \wedge\end{array}$ & $\varepsilon / T V$ & $V / \varepsilon$ & $1 / 7 r$ & $1 \varepsilon / \varepsilon \varepsilon$ & $\begin{array}{c}t=1 \cdot / \Lambda V \\
d f=\Lambda \uparrow \wedge\end{array}$ & $\varepsilon / 1 \varepsilon$ & $N / \varepsilon 7$ & $1 / \pi \varepsilon$ & $|\varepsilon / 7|$ & $\begin{array}{l}t=11 / 0 \\
d f=\wedge r .\end{array}$ & $\varepsilon / \varepsilon r$ & $V / V q$ & $1 / 09$ & $1 \varepsilon / \varepsilon 9$ & GCS \\
\hline $\mathrm{P}<\cdot / \cdot \cdot 1$ & & & & & $\mathbf{P}<\cdot / \cdot \cdot \mathbf{l}$ & & & & & $\mathbf{P}<\cdot / \cdot \cdot \mid$ & & & & & \\
\hline $\begin{array}{l}\mathrm{t}=\mathrm{V} / \mathrm{r} \Lambda \\
\mathrm{df}=\wedge / \varepsilon\end{array}$ & $r \varepsilon / \varepsilon\rceil$ & $94 / 19$ & $r \cdot / \mu \Lambda$ & $110 / 17$ & $\begin{array}{l}t=r / \cdot 1 \\
d f=\lambda r r\end{array}$ & TY/MT & $91 / 11$ & IV/rT & $11 N / \cdot \varepsilon$ & $\begin{array}{l}t=V / I \varepsilon \\
d f=\lambda r r\end{array}$ & $r T / T r$ & $9 Y / \cdot r$ & $19 / \pi \varepsilon$ & $11 V / 20$ & Systol \\
\hline $\mathrm{P}<\cdot / \cdot \cdot 1$ & & & & & $\mathbf{P}<\cdot / \cdot \cdot 1$ & & & & & $\mathbf{P}<\cdot / \cdot \cdot 1$ & & & & & \\
\hline $\begin{array}{l}t=1 / v \wedge \\
d f=\wedge 11\end{array}$ & $1 \pi / 20$ & $0 \wedge / \varepsilon \wedge$ & $|r / \Lambda|$ & $\mathrm{Vo} / \mathrm{O}$ & $\begin{array}{l}t=\varepsilon / 99 \\
d f=\wedge 1 V\end{array}$ & $1 T / 9 V$ & $77 / 79$ & $1 \cdot / 17$ & $V V / I r$ & $\begin{array}{l}t=0 / 01 \\
d f=119\end{array}$ & $1 \varepsilon / N_{0}$ & $7 \varepsilon / \varepsilon \varepsilon$ & $1 \cdot / 91$ & VY/ol & Diastol \\
\hline $\mathrm{P}<\cdot / \cdot \cdot 1$ & & & & & $\mathbf{P}<\cdot / \cdot \cdot 1$ & & & & & $\mathbf{P}<\cdot / \cdot \cdot 1$ & & & & & \\
\hline $\begin{array}{l}t=1 / \Lambda V r \\
d f=\wedge r r\end{array}$ & TO/Tr & $1 \cdot 1 / 79$ & Tr/Tו & $91 / 1 \mathrm{r}$ & $\begin{array}{l}t=1 / N 7 \\
d f=\Lambda r r\end{array}$ & $r \mu / .0$ & $91 / 40$ & $I T / T_{0}$ & $10 / 71$ & $\begin{array}{l}\mathrm{t}=1 / r V \\
\mathrm{df}=\wedge \mathrm{r} \mid\end{array}$ & רותו & $Q Y / T V$ & $\mid r / \varepsilon r$ & $\Lambda V / \cdot r$ & PR \\
\hline $\mathrm{P}=\cdot / \cdot 7 \mathrm{~V}$ & & & & & $\mathrm{P}=\cdot / \cdot \wedge \varepsilon$ & & & & & $P=\cdot / r \mid I$ & & & & & \\
\hline $\begin{array}{c}t=\cdot / \varepsilon \vee \varepsilon \\
d f=\wedge r \varepsilon\end{array}$ & $1 T / T_{0}$ & $19 / \mathrm{Vr}$ & $\varepsilon / \Lambda$. & $r \cdot 101$ & $\begin{array}{l}t=r_{0} \\
1 / d f=\Lambda r \varepsilon\end{array}$ & $1 / 77$ & $|\Lambda / \varepsilon|$ & $\varepsilon / \cdot \wedge$ & $17 / \mathrm{VV}$ & $\begin{array}{c}t=\cdot / 0 \varepsilon r \\
d f=\wedge r \mid\end{array}$ & $9 / v \wedge$ & $I V / 9 T$ & $\varepsilon / \pi r$ & IV/TY & RR \\
\hline $\mathrm{P}=\cdot / 7 \pi \mathrm{V}$ & & & & & $\mathrm{P}=\cdot / \wedge \wedge \varepsilon$ & & & & & $\mathbf{P}=\cdot / \Upsilon \wedge \uparrow$ & & & & & \\
\hline $\begin{array}{l}t=\gamma / \varepsilon r \varepsilon \\
d f=\wedge 17\end{array}$ & $.10 \varepsilon$ & $\mu \mathrm{r} / \mu \varepsilon$ & . 104 & $\mathrm{ru} / \mathrm{st}$ & $\begin{array}{c}t=1 / v \wedge \\
d f=r r\end{array}$ & $\cdot / 29$ & rT/ro & $\cdot / \varepsilon V$ & $r v / 90$ & $\begin{array}{c}t=r / 09 \\
d f=\varepsilon 1\end{array}$ & . /ro & r./11 & $\cdot / 27$ & $r \mathrm{r} / \mathrm{Aq}$ & Temp \\
\hline $\mathrm{P}<\cdot / \cdot \cdot 1$ & & & & & $\mathrm{P}=\cdot / \cdot \wedge 0$ & & & & & $\mathbf{P}<\cdot / \cdot \cdot 1$ & & & & & \\
\hline $\begin{array}{l}t=7 / 70 \\
d f=791\end{array}$ & $1 T / 01$ & NT/MT & r/10 & $9 \varepsilon / 20$ & $\begin{array}{l}\mathrm{t}=.9 \\
/ \mathrm{df}=791\end{array}$ & $9 / 0 \varepsilon$ & $19 / 11$ & $r / 00$ & $97 / 1 V$ & $\begin{array}{l}t=7 / 0 r \\
d f=791\end{array}$ & $10 / 1$ & $\Lambda \cdot / \Lambda V$ & $r / \tau$. & $Q \varepsilon / \varepsilon V$ & SPO2 \\
\hline $\mathrm{P}<\cdot / \cdot \cdot 1$ & & & & & $\mathbf{P}<\cdot / \cdot \cdot 1$ & & & & & $\mathbf{P}<\cdot / \cdot \cdot 1$ & & & & & \\
\hline $\begin{array}{c}t=11 / 71 \mathrm{df}=1 \varepsilon V \\
P<\cdot / \cdot \cdot 1\end{array}$ & $\varepsilon / T V$ & $V / \varepsilon$ & $1 / \pi T$ & $\mid \varepsilon / \varepsilon \varepsilon$ & $\begin{array}{c}\mathrm{t}=\cdot / \varepsilon \wedge \mathrm{df}=1 \varepsilon \vee \\
\mathrm{P}=\cdot / \Gamma \varepsilon 0\end{array}$ & $\mathrm{VQ} / \mathrm{WV}$ & IVO/TV & $77 / \pi 7$ & $10 \mathrm{VNA}$ & $\begin{array}{c}t=\cdot / \wedge \varepsilon \wedge \mathrm{df}=1 \varepsilon\rceil \\
\mathbf{P}=\cdot / r q \wedge\end{array}$ & $\mathrm{W} / 70$ & $\mid V Y / q \varepsilon$ & $77 / 17$ & $10 V / 7 V$ & $\mathrm{BS}$ \\
\hline
\end{tabular}

GCS: Glasgow Coma Scale (GCS), Diastolic pressure: Diastolic blood pressure, Systolic pressure: systolic blood pressure, RR: Respiratory rate, Temp: Temperature, SPO2: oxygen saturation percentage, BS: Blood Sugar, PR: Pulse Rate 
است از بين همه متغيرهايى كه در مدل رگرسيونى وارد

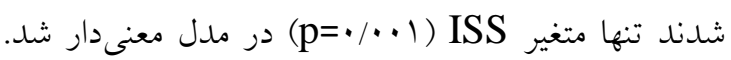
به عبارتى با افزايش يكى واحد در ISS شانس زنده ماند ماندن در مصدومين به اندازه A7/ • كاهش مى يابد.
براى بررسى عوامل مؤثر بر ميزان بقا از مدل ركرسيون

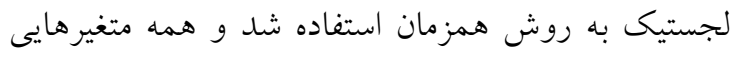

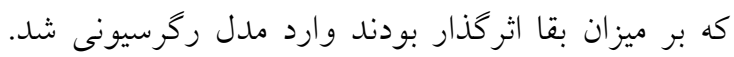
همانطور كه نتايج در جدول شماره ع نشان داده شده

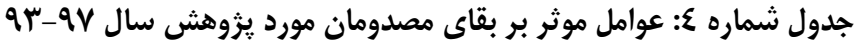

\begin{tabular}{|c|c|c|c|c|c|c|}
\hline 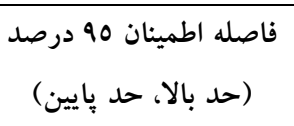 & $\begin{array}{c}\text { EXP } \\
\text { (B) }\end{array}$ & $\mathbf{P}$ & S.E & B & متغيرهاى مستقل & \\
\hline$(\cdot / \cdot\{0, \wedge$ NoV $)$ & . /TYO & . NTV & $1 / \pi \varepsilon v$ & $-\cdot / \varepsilon V \mid$ & سر و كردن & \\
\hline$(\cdot / \varepsilon \wedge \varepsilon, Y Y / Y \wedge \Lambda)$ & r/TAr & $\cdot / T Y \varepsilon$ &.$/ 9 \mathrm{VV}$ & $1 / 1 \wedge 9$ & سينه & \\
\hline$(\cdot / \cdot r \mid, Y / \cdot V r)$ & $\cdot / 707$ & $\cdot / r \cdot r$ & $1 / \cdot 7 V$ & 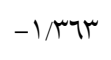 & 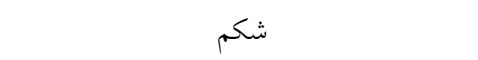 & \\
\hline$(\cdot / V \wedge q, \cdot / Q \varepsilon Y)$ & $\cdot / 1 / T$ &.$/ \cdot 1$ &.$/ .20$ & $-\cdot / 1 \varepsilon q$ & ISS سر، صورت، شكم، اندامها، لكُن و سينه & \\
\hline$(\cdot / \cdot V 7,1 \cdot / r V Y)$ & $\cdot / M 1$ &.$/ 94$ & 1/ror &.$- / T r V$ & 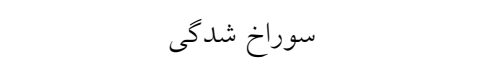 & لحظه رسيدن \\
\hline$(\cdot / \cdot r 7,1 / \wedge 9 \vee)$ & DTMT &.$/ 179$ & $1 / .9 \varepsilon$ & $-1 / 0 \cdot \varepsilon$ & 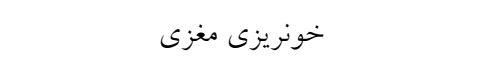 & 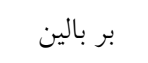 \\
\hline$(\cdot / r \cdot V, \varepsilon N / 9 \mid 0)$ & $r / \backslash \Lambda)$ & $\cdot / \varepsilon \cdot V$ & $1 / \pi 9 \varepsilon$ & $1 / 10 \mathrm{~V}$ & آسيبهاى ريوى & مصدوم \\
\hline$(\cdot / \cdot r q, r / / q r \varepsilon)$ & . $/ 9 \pi r$ &.$/ 97$ & $1 / 717$ & $-\cdot / \cdot 1$ & حمايت تنفسى & \\
\hline$(\cdot / \cdot 00, \varepsilon 9 / \pi 7)$ & 1/70T & $\cdot /$ VVY & INTr & $.10 \cdot r$ & 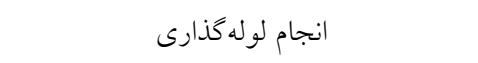 & \\
\hline$(\cdot / I Y 0, r / \neg I V)$ &.$/ T V T$ & $\cdot / 7 \varepsilon r$ & $\cdot / 109$ &.$- / 49 \Lambda$ & فيكس كامل & \\
\hline$(\cdot / \cdot r \mid, r / \wedge \circ \Lambda)$ & $\cdot$ & $\cdot \pi \Lambda$ & $1 / T \varepsilon r$ & $-1 / \cdot 10$ & 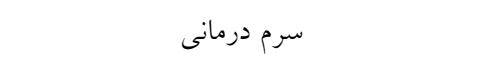 & \\
\hline$(\cdot / \cdot 19,1 r / r \cdot \Lambda)$ & $\cdot / \varepsilon \vee 7$ &.$/ 70 \varepsilon$ & $1 / 707$ & $-\cdot N \varepsilon r$ & وضعيت ريه & \\
\hline$(\cdot / \Gamma \mid r, \Delta \varepsilon / \varepsilon \cdot 0)$ & $r / \varepsilon \cdot 1$ & $\cdot \pi \wedge V$ & $1 / \varepsilon \mid \varepsilon$ & $1 / T Y \varepsilon$ & وضعيت قلب & \\
\hline$(\cdot / r|T,| / K r)$ &.$/ I V V$ & $\cdot / / \mathrm{VV}$ & $\cdot / 279$ & ת זד/. & GCS & \\
\hline$(\cdot / \wedge ৭ \Lambda, 1$ r & $\cdot \pi \varepsilon q$ & $\cdot \pi \varepsilon q$ & .11 .0 & .1 .99 & $\mathrm{SPO} 2$ & \\
\hline$(\cdot / \Gamma\rceil, \wedge \Gamma / \neg \cdot 0)$ & $0 / 200$ & $\cdot / K Y I$ & $1 / \pi \wedge V$ & $1 / 797$ & وضعيت مردمى & لحظه تحويل \\
\hline$(\cdot / \bullet$ Or, Ir/TrA $)$ & $\cdot / \Lambda \mu$ & $\cdot / 1990$ & $1 / \varepsilon \mid r$ &.$- / 117$ & وضعيت قلب & به بيمارستان \\
\hline$(\cdot / \neg \varepsilon V, \tau / \wedge \Gamma \Psi)$ & $r / 1 \cdot r r$ & $\cdot / r / 7$ & $\cdot / 7 \cdot 1$ & $\cdot / V \varepsilon r$ & GCS & \\
\hline$(\cdot / \varepsilon V V, Y / \varepsilon / q)$ & $1 / \cdot v \varepsilon$ & 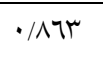 & $\cdot / \varepsilon / \varepsilon$ & $\cdot / \cdot v 1$ & GCS & \\
\hline$(\cdot / 79 r, 1 / / V r)$ &.$/ 9 \cdot 1$ & $\cdot / \varepsilon{ }^{\prime} \wedge$ &.$/ 1 r \varepsilon$ & $-\cdot / 1 \cdot \varepsilon$ & $\mathrm{SPO} 2$ & \\
\hline$(1 / \cdot, 1 / \cdot r)$ & $1 / \cdot 11$ &.$/ .0 \mathrm{~V}$ &.$/ .7$ &.$/ .11$ & PLT & بيمارستان \\
\hline$(\cdot / \cdot r, V / / r r o)$ & -/2To & $\cdot / V \varepsilon \varepsilon$ & T/רוT & $-\cdot / 100$ & تزريق پِلاسما & \\
\hline$(\cdot / \cdot 1,1 / \varepsilon r q)$ & $\cdot /|r|$ & .1 .90 & 1/YTT & $-T / 1 \cdot 9$ & جست تيوب & \\
\hline$(\cdot / \Lambda \wedge \vee, \varepsilon \wedge / \Gamma \cdot \eta)$ & T/OEV & .1 .70 & $1 / \cdot r$ & 1/AVa & تزريق خون & \\
\hline$(\cdot / \wedge 0,1 T / \Sigma \cdot 7)$ & T/MAV & $\cdot \pi V V$ & $\cdot / 117$ & - MAY & كج گيرى & \\
\hline
\end{tabular}

GCS:Glasgow Coma Scale (GCS), SPO2: oxygen saturation percentage, PLT: PLATELET

است كه شانس زنده ماندن در بيمارانى كه نوع ضايعه آن

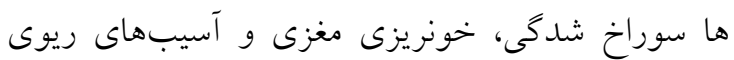

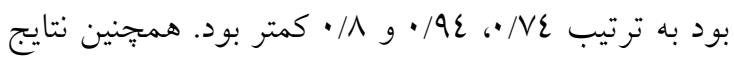

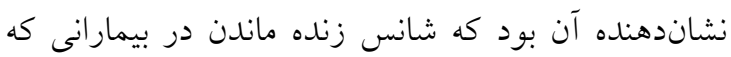
داراى محل آسيب در سر و گردن، سينه و شكم بودند به نهان

\section{بحث و نتيجه كيرى}

طبق نتايج مطالعه حاضر محل آناتوميكى در تمامى موارد و نوع تروما با بقا ارتباط داشت. بررسى ارتباط بقا با نوع

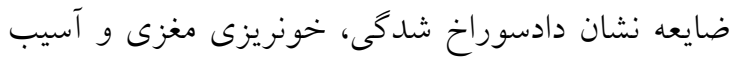

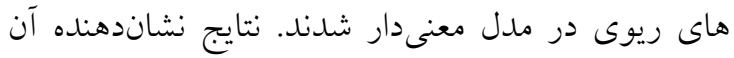


جه شدت آسيب بيشتر باشد، احتمال زنده ماندن كمتر است. با افزايش يك واحد در ISS شانس زنده ماندن در مصدومين به اندازه 1/1/ • كاهش مى يابد. مقدار

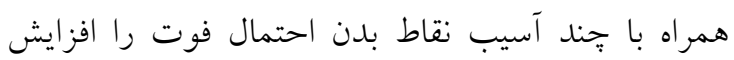

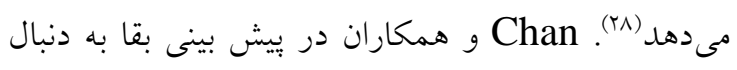
تروما در جمعيت آسيا در هنگ كنغ نشان دادند ميانخين در مصدومان فوت شده بيشتر از مصدومان بهبود

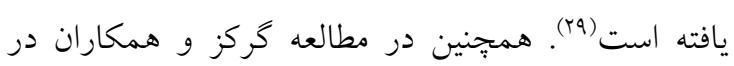

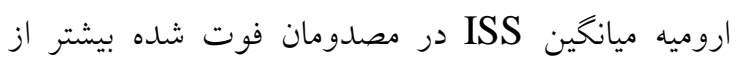

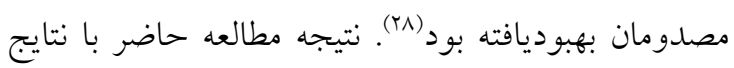
يُؤهشهاى بيان شده همخوانى دارد. در مطالعه موسىزاده در تبريز نيز مؤلفههاى ISS در مصدومان مدان

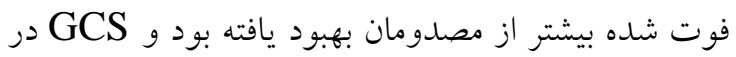

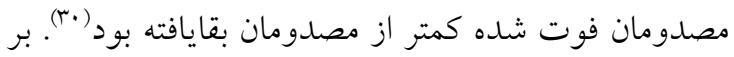

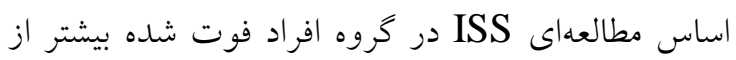

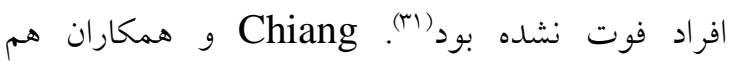
كزارش كردند كه در تايوان بايين بودن ISS يِيش بينى كننده بقاى سالمندان دجار تروما بوده كه مشابه افراد

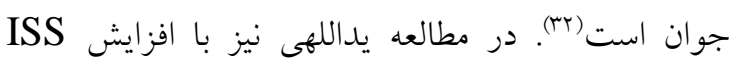

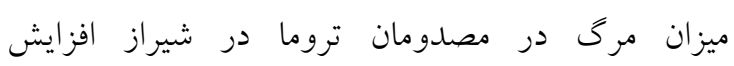

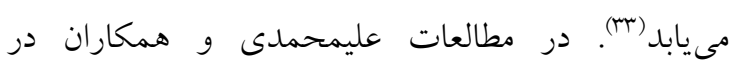

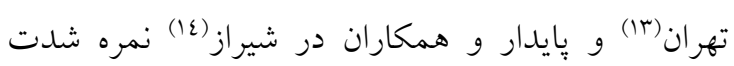

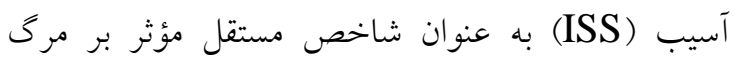

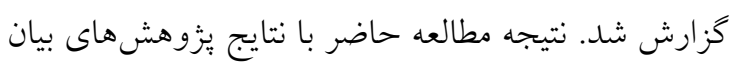
شده همخوانى دارد. از محدوديتهاى اين مطالعه مىتوان به جمع آورى دادهها

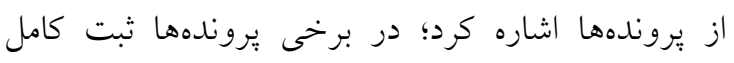

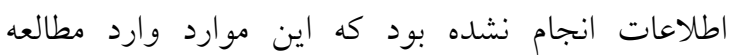

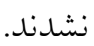
با توجه به بالا بودن آمار تصادفات ضرورى است نسبت

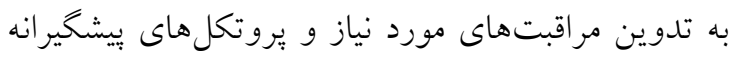
از مرگ به دنبال تروما متناسب با شدت صدمه بيماران همت كماشت. با توجه به اين كه علت بيشتر

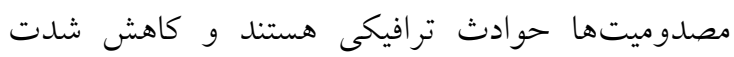

ترتيب به اندازه س// •، V7/ و و • • • كاهش مىيابد.

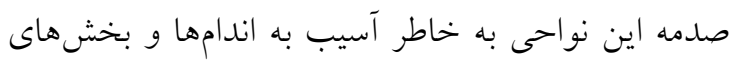

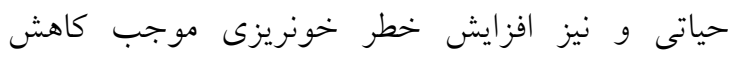
احتمال بقا مىشود. جّنان كه در مطالعه Neslihan نيز

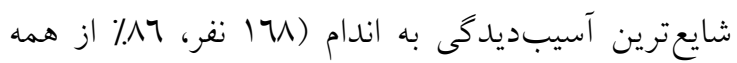

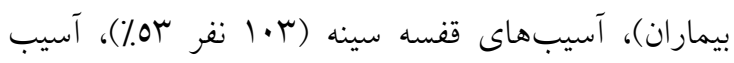

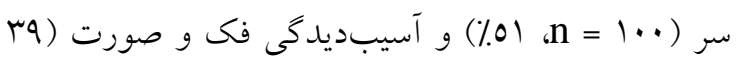

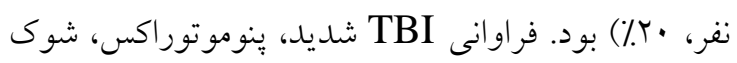

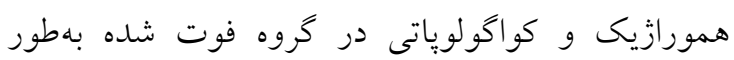
معنى دارى بيشتر از كروه بازمانده بود (10).

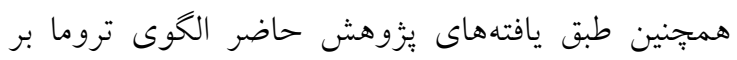

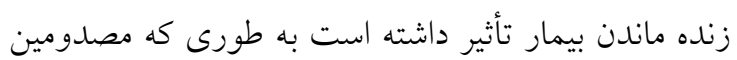
داراى تروماى نافذ 17/1 درصد و مصدومينى كه داراى

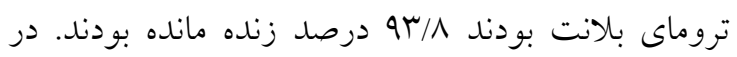
مطالعه يعقوبى نوتاش و همكاران كه بر روى تمانى بردن

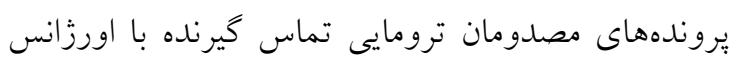

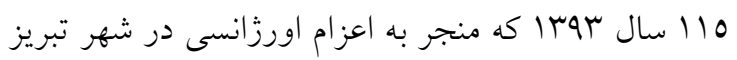

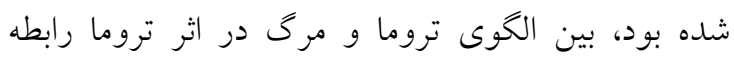

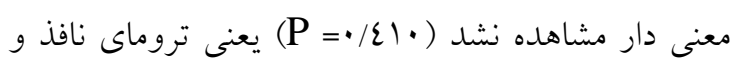
بلانت به طور مؤثر بر مرى در اثر تروما تأثير ندارند.

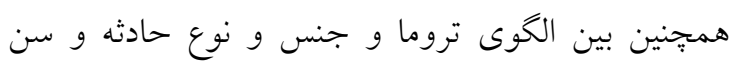

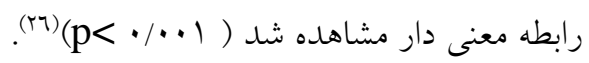

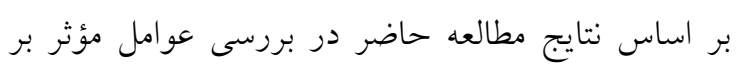

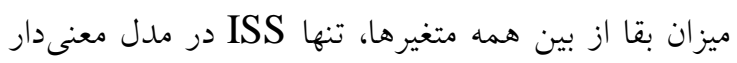

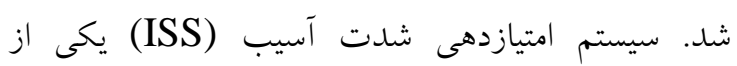

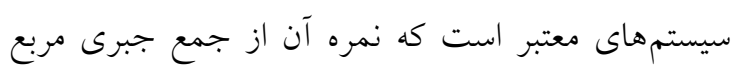
بالاترين مقادير (AIS) از سه منطقه بدن، كه بيشترين

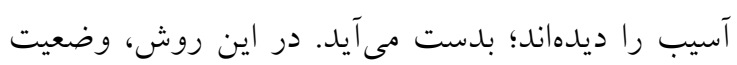
بيمار از نظر آسيب به شش قسمت مهم بدن (سر و كردن،

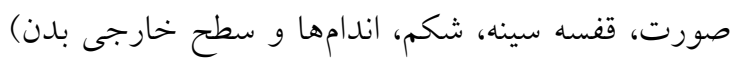

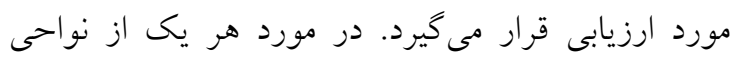

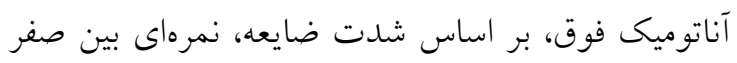
(عدم وجود ضايعه) تا شش (در مورد ضايعات كشنده)

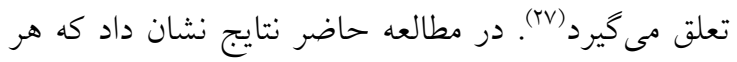




$$
\begin{aligned}
& \text { در ارتباط با فرهنگ ترافيكى و حمل و نقل و نيز افزايش } \\
& \text { آسيب عامل مهم در حفظ بقاى بيماران است، ضرورى } \\
& \text { بقاى مصدومين تروما در اين استان استفاده كنند. نتايج } \\
& \text { اين مطالعه مىتواند براى تصميمگيرندكان و مسئولين } \\
& \text { اورزانس كشور در تعيين عوامل مرتبط با بقاى بيماران }
\end{aligned}
$$

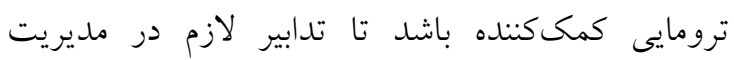

$$
\begin{aligned}
& \text { شرايط بيماران در اورزانس بيش بيمارستانى را اتخاذ }
\end{aligned}
$$

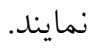

$$
\begin{aligned}
& \text { تعارض منافع: هيج گونه تعارض منافع توسط نويسندگان }
\end{aligned}
$$

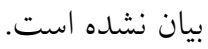

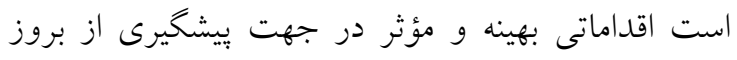

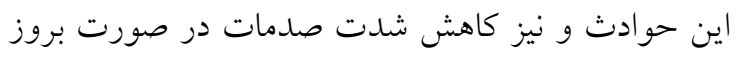

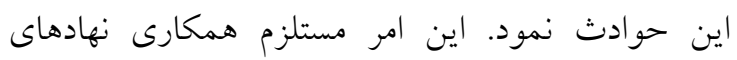

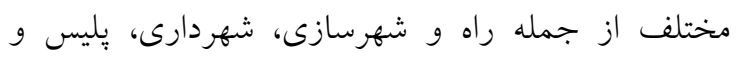

$$
\begin{aligned}
& \text { ارائه دهندكان خدمات بهداشتى و درمانى است. همينين } \\
& \text { در صورت بروز حوادث، مهم است كه با استفاده از روش } \\
& \text { هاى مناسب ارزيابى در شناسايى وسعت صدمه و متعاقبا } \\
& \text { تنظيم راهبردهاى صحيح درمانى مراقبتى در راستاى بقاى } \\
& \text { مصدومين اقدام نمود. هرجند اين مطالعه در استان قزوين } \\
& \text { انجام شده است و يافتههاى آن قابل تعميم و استفاده } \\
& \text { تقدير و تشكر } \\
& \text { توسط مسئولين و مديران حوزه ارائه خدمات اورزانس در لئس } \\
& \text { اين استان است. حوادث و تروما در سنين جوان و مولد } \\
& \text { جامعه تأثير بيشترى دارد و در بين حوادث، حوادث } \\
& \text { ترافيكى بيشترين سهم را دارند. بنابراين از نتايج اين }
\end{aligned}
$$

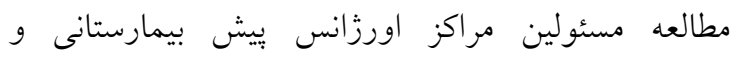

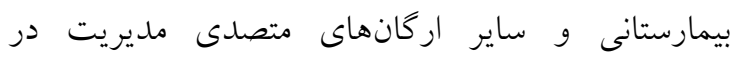

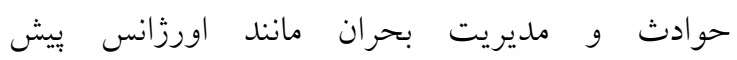

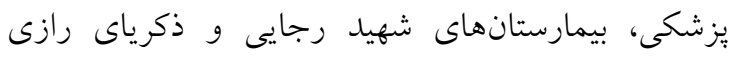

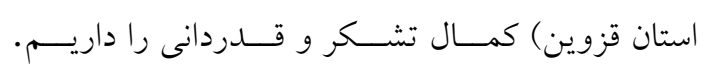

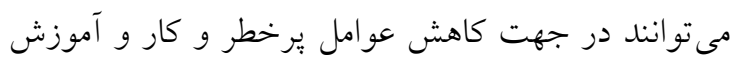

\section{Rreferences}

1. Dziadzko V, Dziadzko MA, Johnson MM, Gajic O, Karnatovskaia LV. Acute psychological trauma in the critically ill: Patient and family perspectives. Gener Hospital Psych. 2017;47:68-74.

2. Geeraedts Jr LM, Kaasjager HA, Van Vugt AB, Frölke JP. Exsanguination in trauma: a review of diagnostics and treatment options. Injury. 2009;40(1):11-20.

3. WHO. Road traffic injuries 2018. Available from: http://www.who.int/news-room/factsheets/detail/road-traffic-injuries.

4. Ansari M, Bayan L, Gorji A. The impact of road accidents on brain injury. The Neuroscience Journal of Shefaye Khatam. 2016;4(3):103-10. [Persian]

5. World Health Organization. Global status report on road safety 2013: supporting a decade of action: summary. World Health Organization; 2013.

6. Khankeh HR, Alinia SH, Masoumi GH, Ranjbar M, Daddoost L, Hosseini SA, Fallahi Khoshknab M, Castren M. Prehospital services by focus on road traffic accidents: Assessment developed and developing countries. Journal of Health Promotion Management. 2013;2(2):71-9. [Persian]

7. Aghajani M, Shahrami A, Kolivand P, Saberinia A, Masoumi G, Sarvar M. Check the Program Upgrading the Air Emergency Services in the Health Transformation Plan: A Review of the Background, Necessity, Results and Challenges. Hakim Research Journal. 2017;20(3):175-85. [Persian] 
8. Dadashzadeh A, Dehghannejhad J, Shams Vahdati S, Soheili A, Sadeghi Bazarghani H. The nature of prehospital medical interventions delivered to traumatic patients in Tabriz. Nursing And Midwifery Journal. 2017;15(3):159-67. [Persian]

9. Pourshaikhian M, Jahangiri K, Kazemnejad E, Vatankhah S. Pre-hospital emergency medical services: the analysis of EMS ambulances equipment in Rasht city. Scientific Journal of Rescue and Relief. 2014;6(1):55-65. [Persian]

10. Bahadori M, Ghardashi F, Izadi AR, Ravangard R, Mirhashemi S, Hosseini SM. Pre-hospital emergency in Iran: A systematic review. Trauma monthly. 2016;21(2).

11. Harmsen AM, Giannakopoulos GF, Moerbeek PR, Jansma EP, Bonjer HJ, Bloemers FW. The influence of prehospital time on trauma patients outcome: a systematic review. Injury. 2015;46(4):602-9.

12. Radmehr M, Haghighi S, Basir Ghafouri H, Abbasi S, Farsi D, Amiri H, Kianmehr N, Mofidi M. The importance initial body temperature in critically ill trauma patients on to ICUs in prediction of the outcome. Journal of Jahrom University of Medical Sciences. 2013;11(3):49-55. [Persian]

13. Alimohammadi H, Bidarizerehpoosh F, Mirmohammadi F, Shahrami A, Heidari K, Sabzghabaie A, Keikha S. Cause of emergency department mortality; a case-control study. Emergency. 2014;2(1):30.

14. Paydar S, Moghaninasab A, Asiaei E, Jahromi GS, Bolandparvaz S, Abbasi H. Outcome of patients underwent emergency department thoracotomy and its predictive factors. Emergency. 2014;2(3):125.

15. Fisher JD, Freeman K, Clarke A, Spurgeon P, Smyth M, Perkins GD, Sujan MA, Cooke MW. Patient safety in ambulance services: a scoping review. 2015.

16. Andruszkow H, Schweigkofler U, Lefering R, Frey M, Horst K, Pfeifer R, Beckers SK, Pape HC, Hildebrand F. Impact of helicopter emergency medical service in traumatized patients: which patient benefits most?. PLoS One. 2016;11(1):e0146897.

17. Galvagno Jr SM, Sikorski R, Hirshon JM, Floccare D, Stephens C, Beecher D, Thomas S. Helicopter emergency medical services for adults with major trauma. Cochrane database of systematic reviews. 2015(12):CD009228.

18. Madiraju SK, Catino J, Kokaram C, Genuit T, Bukur M. In by helicopter out by cab: the financial cost of aeromedical overtriage of trauma patients. J Surg Res. 2017;218:261-70.

19. Akhtari AS, Jafari NS, Kariman H, Amini A, Monsef V, Noorizadeh M, Gholizadeh N. The coast and benefits of helicopter emergency medical services instead of the ground unit in traumatic patients: A cost-effectiveness analysis. Health. 2013;5(5):903.

20. Behbahani H, Effati M, Mortezaei S. Providing a Method for Accident Severity Analysis Using Geospatial Clustering Functions and Decision Tree, Case Study: Qazvin-Loshan Freeway. Amirkabir Journal of Civil Engineering. 2019;52(6):7. [Persian]

21. Hill CS, McLean AL, Wilson MH. Epidemiology of pediatric traumatic brain injury in a dense urban area served by a helicopter trauma service. Pediatric Emergency Care. 2018;34(6):426-30.

22. Zare M, Kargar S. Evaluation of prehospital care in management of traumatic patients referred to Shahid Rahnemoun and Afshar Hospitals of Yazd. SSU_Journals. 2006;13(5):25-30. [Persian]

23. Salehi SH, Razmjou I. Prognosis assessment of The Injury Severity Score in traffic accidents. Iranian South Medical Journal (ISMJ). 2006;9(1):45-50. [Persian]

24. Greenspan LO, Mclellan BA, Greig H. Abbreviated injury scale and injury severity score: A scoring chart. The Journal of trauma. 1985;25(1):60-4.

25. Yucel N, Ozturk Demir T, Derya S, Oguzturk H, Bicakcioglu M, Yetkin F. Potential risk factors for in-hospital mortality in patients with moderate-to-severe blunt multiple trauma who survive initial resuscitation. Emerg Medic Int. 2018;2018.

26. Yaghoobi Notash A, Yaghoobi Notash A, Ahmadi Amoli H, Borna L, Yaghoobi Notash A. Evaluation of trauma patterns and their related factors in Besat Hospital in Sanandaj in 2012. Scientific Journal of Kurdistan University of Medical Sciences. 2014;19(1):99-107. [Persian]

27. Civil ID, Schwab CW. The Abbreviated Injury Scale, 1985 revision: a condensed chart for clinical use. The Journal of trauma. 1988;28(1):87-90.

28. Garkaz O, Salari Lak S, Mehryar HR, Khalkhali HR. Study ending of hospitalized traffic accidents injured in Urmia Imam Khomeini hospital by using TRISS method. Scientific Journal of Forensic Medicine. 2019;25(1):23-9. [Persian] 
29. Chan CK, Yau KK, Cheung MT. Trauma survival prediction in Asian population: a modification of TRISS to improve accuracy. Emerg Medic J. 2014;31(2):126-33.

30. Mousazadeh Y. Developing a Hospital Performance Assesment Model for Patients Management with Trraffic Injures (Doctoral dissertation, Tabriz University of Medical Sciences, School of Management and Medical Informatics). 2019.

31. Davtalab Esmaeili E, Sadeghi-Bazargani H, Shams Vahdati S, Shokouhi G, Safaiyan A, Salari Lak S. Assessment of survival and hospital care quality in patients with traffic injury in east Azerbaijan. Trauma Monthly. 2017;22(5). [Persian]

32. Chiang WK, Huang ST, Chang WH, Huang MY, Chien DK, Tsai CH. Mortality factors regarding the injury severity score in elderly trauma patients. Int J Gerontol. 2012;6(3):192-5.

33. Yadollahi M. A study of mortality risk factors among trauma referrals to trauma center, Shiraz, Iran, 2017. Chin J Traumatol. 2019;22(4):212-8. 